OPEN ACCESS

Edited by:

Junjie Xiao

Shanghai University, China

Reviewed by:

Paulo M. Dourado,

University of São Paulo, Brazil

Jianqing She,

The First Affiliated Hospital of Xi'an

Jiaotong University, China

*Correspondence:

Jing Wang

wangjing@ibms.pumc.edu.cn

Hongmei Zhao

pumczhaohm@sina.com

Specialty section:

This article was submitted to General Cardiovascular Medicine,

a section of the journal

Frontiers in Cardiovascular Medicine

Received: 06 January 2021

Accepted: 31 March 2021

Published: 05 May 2021

Citation:

Li ZW, Zhao HM and Wang J (2021) Metabolism and Chronic Inflammation:

The Links Between Chronic Heart Failure and Comorbidities.

Front. Cardiovasc. Med. 8:650278.

doi: $10.3389 / f C v m .2021 .650278$

\section{Metabolism and Chronic Inflammation: The Links Between Chronic Heart Failure and Comorbidities}

\author{
Zhiwei Li, Hongmei Zhao* and Jing Wang * \\ Department of Pathophysiology, State Key Laboratory of Medical Molecular Biology Institute of Basic Medicine, Chinese \\ Academy of Medical Sciences, School of Basic Medicine, Peking Union Medical College, Beijing, China
}

Heart failure (HF) patients often suffer from multiple comorbidities, such as diabetes, atrial fibrillation, depression, chronic obstructive pulmonary disease, and chronic kidney disease. The coexistance of comorbidities usually leads to multi morbidity and poor prognosis. Treatments for HF patients with multi morbidity are still an unmet clinical need, and finding an effective therapy strategy is of great value. HF can lead to comorbidity, and in return, comorbidity may promote the progression of HF, creating a vicious cycle. This reciprocal correlation indicates there may be some common causes and biological mechanisms. Metabolism remodeling and chronic inflammation play a vital role in the pathophysiological processes of HF and comorbidities, indicating metabolism and inflammation may be the links between HF and comorbidities. In this review, we comprehensively discuss the major underlying mechanisms and therapeutic implications for comorbidities of HF. We first summarize the potential role of metabolism and inflammation in HF. Then, we give an overview of the linkage between common comorbidities and HF, from the perspective of epidemiological evidence to the underlying metabolism and inflammation mechanisms. Moreover, with the help of bioinformatics, we summarize the shared risk factors, signal pathways, and therapeutic targets between $\mathrm{HF}$ and comorbidities. Metabolic syndrome, aging, deleterious lifestyles (sedentary behavior, poor dietary patterns, smoking, etc.), and other risk factors common to HF and comorbidities are all associated with common mechanisms. Impaired mitochondrial biogenesis, autophagy, insulin resistance, and oxidative stress, are among the major mechanisms of both HF and comorbidities. Gene enrichment analysis showed the PI3K/AKT pathway may probably play a central role in multi morbidity. Additionally, drug targets common to HF and several common comorbidities were found by network analysis. Such analysis has already been instrumental in drug repurposing to treat HF and comorbidity. And the result suggests sodium-glucose transporter-2 (SGLT-2) inhibitors, $\mathrm{IL}-1 \beta$ inhibitors, and metformin may be promising drugs for repurposing to treat multi morbidity. We propose that targeting the metabolic and inflammatory pathways that are common to HF and comorbidities may provide a promising therapeutic strategy.

Keywords: heart failure, comorbidities, metabolism, chronic inflammation, reactive oxygen species, mitochondria 


\section{INTRODUCTION}

Heart failure (HF) is a global public health problem that affects more than 26 million people worldwide and causes a heavy health burden $(1,2)$. The prevalence of HF was $1.3 \%$ in Chinese adults (an estimated 13.7 million), in which $23 \%$ of patients had HF with preserved ejection fraction (EF), (HFpEF), $23 \%$ had HF with middle-range EF (HFmrEF), and about $54 \%$ had reduced ejection fraction (HFrEF) (3). Due to the aggravation of aging, the incidence of HF is rising, and HF is associated with increased mortality, morbidity, and hospitalization (4).

HF often coexists with multiple comorbidities. The reported prevalence of comorbidities varied with HF severity (5). As shown in Figure 1, we summarized the prevalence of major comorbidities according to the different organs and systems involved, such as hypertension (65\%), atrial fibrillation (45\%), chronic obstructive pulmonary disease (COPD)/asthma(40\%), iron deficiency (30\%), diabetes (40\%), chronic kidney diseases (CKD) (25\%), obesity (45\%) $(6,7)$, ischaemic heart disease $(50 \%)$, hyperlipidaemia (55\%) (8), depression (40\%) (9-11), sleep apnea (40\%) (12), sarcopenia (40\%) (13) and liver dysfunction (10\%) (14). The high prevalence of multi morbidity is associated with poor prognosis and heavy heath burdens, and therapy for multi morbidity in HF is still a challenge (15). However, the treatment of comorbidities may have cardiovascular side effects. Therefore, understanding the underlying mechanisms and finding potential strategies for both HF and comorbidities is worthwhile.

Metabolism and inflammation play an essential role in the pathophysiology of HF and its associated comorbidities, which may be the link between them. In this review, we summarized the role of metabolism and inflammation in HF and its most common comorbidities, and review their possible links, including shared risk factors, signal pathways, and therapeutic targets.

\section{METABOLIC REMODELING FROM NORMAL TO FAILING HEART IS BOTH CAUSE AND EFFECT OF HEART FAILURE}

The heart requires a high rate of ATP production and turnover to fuel its continuous mechanical work, and it has become common knowledge that the failing heart is an "engine out of fuel" (16). We give an overview of the pathological cardiac metabolic remodeling from physiological condition to heart failure in Figure 2, including glucose, fatty acid (FA), amino acid, and ions metabolisms. These metabolic changes all affect cardiac energy metabolism either by directly participating in or indirectly regulating mitochondrial metabolism.

\section{Normal Cardiac Energy Metabolism Has Compensatory Capacity}

Under normal physiological conditions, the heart cycles about $6 \mathrm{~kg}$ of ATP every day (16). Regulation of cardiac energy metabolism is through substrate alteration. The substrate mainly consists of fatty acids (FAs), glucose, pyruvate, lactate, and ketone bodies. Glucose and fatty acid metabolism are major contributors to cardiac energy metabolism.
At rest, about $15-25 \%$ of the heart's maximum energy loading capacity is used (17). The cardiac energy metabolic pathway can be altered in only a few seconds through substrate alterations when shifting from rest to acute stress such as exercise or ischemia, or after glycogen stores have been depleted when fasting. In the normal heart, about $60-90 \%$ (depending on energy demand) of the cardiac energy budget is produced by FA $\beta$-oxidation, and the rest is produced by the pyruvate and tricarboxylic acid (TCA) cycle (18). Under non-ischemic conditions, more than $95 \%$ of the ATP in the normal heart comes from oxidative phosphorylation of FAs, glucose, and lactate in mitochondria, while in a fasting state, as the energy demand increases, there is a substrate shift from FAs to glucose (FAs produce about $70 \%$ of the ATP and glucose produces $20 \%$ ) (17).

There is an auto-balance mechanism of glucose and fatty acid oxidation (FAO) pathways in the energy substrate that called the "Randle cycle," in which the activation of FAO would inhibit glucose uptake, whereas the increased utilization of glucose inhibits FAO, and inhibiting FAO increase glucose oxidation compensatorily (19). This regulation is mainly through an increase in plasma insulin level and the activation of the AMP-activated protein kinase (AMPK) pathway. Insulin would increase glucose uptake and activate the phosphatidylinositol 3kinase (PI3K)/AKT pathway, and finally increases myocardial contractility. Glucose uptake is an insulin-dependent process because glucose transporters (GLUT1/GLUT4) are sensitive to insulin. The activation of AMPK promotes both FA and glucose oxidation which increases cardiac energy. Moreover, AMPK inhibits ATP-consuming processes like protein synthesis (20).

\section{Altered Energy Metabolic Substrate Utilization Is the Major Metabolic Remodeling in Heart Failure}

The metabolic remodeling in the failing heart is similar to the alterations from the non-ischemic to the ischemic condition, as mentioned above, and may well be a protective compensatory mechanism to use more of its capacity. However, long term sustained high energy loading would cause some toxic substances to accumulate, which in turn may contribute to the progress of $\mathrm{HF}$ and comorbidities. In most cases, FAO decreases and glycolysis increases rapidly in HF, except for advanced and diabetic HF where FAO increases $(18,21,22)$, this is because mitochondrial dysfunction in HF causes decreased expression and activity of enzymes associated with mitochondrial FAO (23). Several key enzymes of FAO are regulated by transcript factor peroxisome proliferator-activated receptors (PPARs). The decrease of FAO could be mainly explained by the activation of PPAR $\gamma$ and reduced activity of PPAR $\alpha$ (18). Insulin plays an important role in substrate shift progression. Therefore, in cases of insulin resistance, such as diabetic HF or advanced HF, FAO is increased by activating PPAR $\alpha$ signaling (22). Myocardial uptake of FA usually increases in HF. The imbalance of increased FA uptake and impaired utilization of FAs in HF results in FA accumulation. Accumulated FAs cause lipotoxicity and worsen HF by promoting mitochondrial dysfunction and apoptosis, and contributes to the development of insulin resistance (18). 


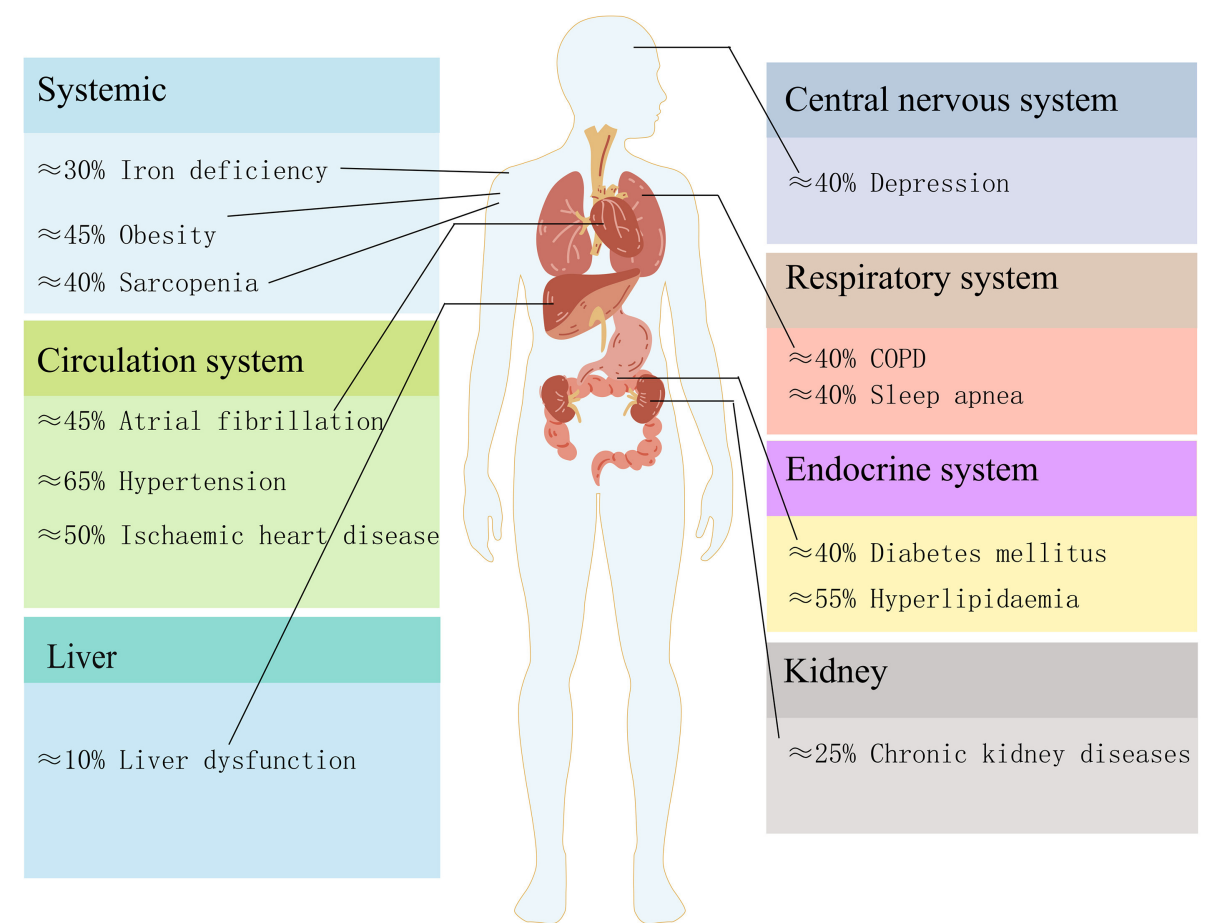

FIGURE 1| The estimated prevalence of heart failure comorbidities in different organs and systems.

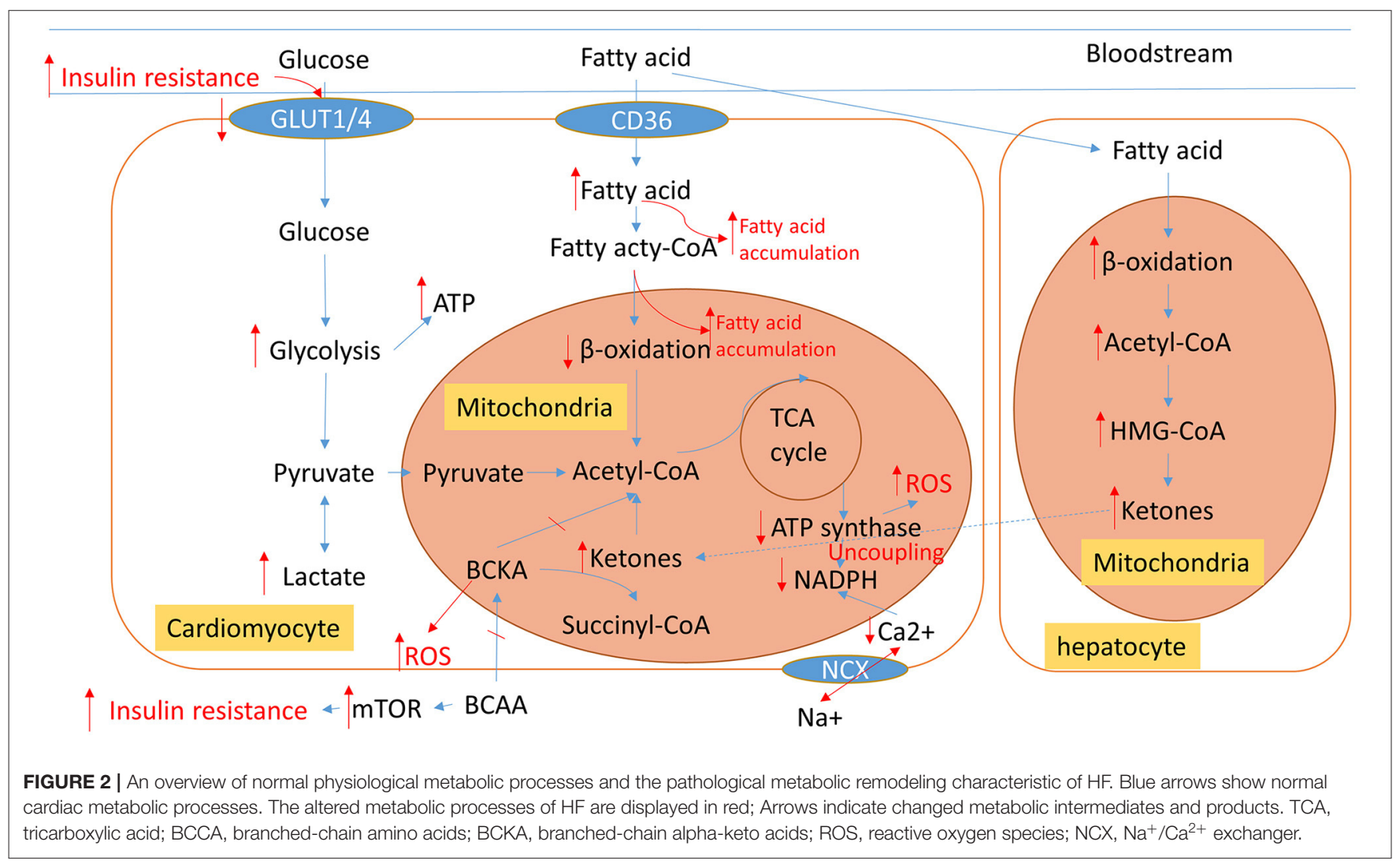


Targeting the FAO pathway is an emerging treatment for HF (24), but the significance of the shift from FAO to glucose metabolism remains controversial and there have two opposite therapeutic strategies: inhibit or facilitate FA utilization. The two therapeutic strategies are not contradictory because they both reduce the cardiac accumulation of FAs, one is by reducing the uptake of FAs and the other is by increasing the catabolism of FAs. Drugs targeted inhibition of FAO may be classified into 3 categories: (1) $\beta$-oxidation inhibition, such as malonyl-CoA decarboxylase inhibitors, (2) mitochondrial FA uptake inhibition, such as the carnitine palmitoyl transferase 1 inhibitor (CPTI), (3) plasma membrane FA uptake reduction by inhibiting related proteins, such as in the case of CD36 (the major FA transporter) or fatty acid-binding protein (FABP). CD36 inhibitor is still under preclinical investigations. However, considering that glucose provides less capacity for energy production than FAs (one FA molecule produces 120-130 ATP, while one glucose molecule produces 30-32 ATP) (22), there is an opposite opinion, which asserts that the heart reverting back to using FA may have therapeutic value for HF, such as by targeting GLUT4 to inhibit glycolysis or activate the AMPK pathway by phosphorylation to increase FAO. Studies have confirmed that reverting to the use of FA has a cardio protective effect $(22,25)$. Restoration of FAO could improve heart function, possibly via reduced cardiac lipotoxicity (26).

Mitochondria are a physiological source of reactive oxygen species (ROS). They are generated in the electron transport chain (ETC) during respiration, and eliminated by NADPH dependent enzyme systems, forming a "redox-optimized ROS balance" (19). The deficit in energy would cause the uncoupling of oxidative phosphorylation, and cause an increase in reactive oxygen species (ROS) and oxidative stress (27). ROS, in return, inactivates several enzymes of the TCA cycle (19).

In addition, liver energy metabolism also participates in the process of HF. Ketone bodies synthesized in liver mitochondria, especially $\beta$-hydroxybutyrate, the so-called super fuel, are more efficient than FAs or glucose. The failing heart adaptively consumes more ketone bodies (28) and this is believed to be beneficial $(23,29)$.

\section{Amino Metabolism Dysfunction Indirectly Affects Cardiac Energy Metabolism}

More glutamine is consumed in HF because it is the most abundant secreted amino acid (28), but branched-chain amino acids (BCAAs) played a more important role in HF. In healthy individuals, BCAAs are essential nutrition for mitochondrial biogenesis, and dietary supplementation of BCAAs has cardio protective effects (30-32). However, BCAA catabolic metabolism is impaired in HF, leading to the accumulation of BCAAs and branched-chain alpha-keto acids (BCKAs) (33). The accumulated BCAAs and their catabolic intermediates have a cardiotoxic effect. BCAA accumulation could result in insulin resistance by activating the mTOR pathway $(34,35)$, and accumulated BCKAs would increase reactive oxygen species (ROS) (36). Furthermore, $\mathrm{BCAA}$ is reported to be a potential therapeutic target for $\mathrm{HF}$ (37). BCAAs are not a major source of cardiac energy (below 5\%)
(28). but may have important indirect regulatory roles in energy metabolism as they affect mitochondrial biogenesis and BCAA toxicity affects energy metabolism.

\section{Ion Metabolism Induces Heart Failure by Regulating Energy Metabolism}

Sodium $\left(\mathrm{Na}^{+}\right)$and calcium $\left(\mathrm{Ca}^{2+}\right)$ ions are closely linked to HF. Elevated intracellular $\mathrm{Na}^{+}$can lead to cardiac energy metabolic shift from FAO to glycolysis (38). The reninangiotensin-aldosterone (RAAS) system has evolved to retain $\mathrm{Na}^{+}$homeostasis and RAAS-blockers have been widely used in $\mathrm{HF}$ therapy. In HF, tubular cells are often hypertrophic and $\mathrm{Na}^{+}$ reabsorption increases. Sodium-glucose transporter-2 (SGLT-2) is a recently discovered diuretic agent that could improve the outcome of $\mathrm{HF}$ (39). Increases in the $\mathrm{Na}^{+} / \mathrm{H}^{+}$exchanger may explain the phenomenon of the elevated $\mathrm{Na}^{+}$level in $\mathrm{HF}(40)$. $\mathrm{Ca}^{2+}$ is required for cardiac diastolic function (41). In fact, $\mathrm{Ca}^{2+}$ signaling plays an essential role in regulating mitochondrial ATP production (42). $\mathrm{Ca}^{2+}$ is a second messenger in various cells and is regulated by ion channels, ion exchangers, pumps (ATPases), and $\mathrm{Ca}^{2+}$-binding proteins (43). The dysfunction of a sarcoplasmic reticulum $\mathrm{Ca}^{2+}$-release channel, ryanodine receptor, can cause calcium leakage and mitochondrial damage, which contribute to the progression of $\mathrm{HF}(44) . \mathrm{Na}^{+}$is associated with $\mathrm{Ca}^{2+}$ uptake and $\mathrm{Ca}^{2+}$ related myofilament contraction through $\mathrm{Na}^{+} / \mathrm{Ca}^{2+}$ exchange (45).

\section{The Clinical Significance of Metabolic Remodeling: A Double-Edged Sword}

Metabolic remodeling is a major pathophysiologic character of HF, but whether it is the cause or result of the HF, and whether it is maladaptive or adaptive is still controversial (46). Why have drugs both targeting inhibition and promotion of metabolic remodeling been used for the treatment of heart failure, and are both able to alleviate HF symptoms? FA or glucose, which is the superior energy substrate? We think that metabolic remodeling has a double effect: On one hand, metabolic remodeling is thought to be an adaptive compensatory mechanism. First, the shift toward glucose metabolism improves myocardial contractile efficiency by increasing the stoichiometric ratio of ATP production to oxygen consumption and reducing oxygen waste (47). Although glucose has a lower energy capacity, the shift is not due to a lack of substrate availability because the coronary circulation is able to provide an excess of substrates (47), and glycolysis produces ATP much faster than other ways, as epitomized by the Warburg effect (48). Second, similar metabolic remodeling can also be seen in the physiological remodeling of the heart. Many pathways, such as the activation of the AMPK and PI3K pathways, which have protective roles, are active in both physiological and pathological cardiac remodeling (20). On the other hand, metabolic remodeling is harmful when toxic substances such as accumulated excess intracellular FAs and ROS are increased, which may worsen HF and cause comorbidities. Recent evidence suggests that the accumulation of toxic intermediates, rather than alterations of substrate 
utilization or ATP deficit per-second, is responsible for cardiac dysfunction (18).

\section{CHRONIC INFLAMMATION}

\section{The Role of Inflammation in Heart Failure}

$\mathrm{HF}$ is usually accompanied by highly elevated circulating pro-inflammatory cytokines, such as IL-1 $\beta$, IL-6, IL-8, TNF$\alpha$, NF-кb, etc. However, the role of inflammation in $\mathrm{HF}$ has long been controversial. Because most traditional antiinflammatory drugs failed in clinical HF therapies, inflammation was considered to not be a cause, but a complication of HF. The importance of inflammation in HF was not widely accepted until the success of canakinumab, an IL-1 $\beta$ inhibitor, which significantly improved the prognosis of HF. The effect of it and other anti-cytokine drugs indicates the role of inflammation in HF (49). Moreover, Soluble suppression of tumorigenesis2(sST2) and galectin-3 are inflammatory biomarkers associated with fibrosis in HF, which have reportedly even better prognoses than NT-pro-BNP, an HF biomarker not directly associated with inflammation $(50,51)$. Having established the causal role of inflammation in HF, in the following, we give an overview of inflammation in cardiac remodeling and various comorbidities.

\section{The Immune Response Causes Systemic Inflammation}

Both the innate and adaptive immune systems have a pro-inflammation role in HF. The immune response triggered inflammation mechanism is called immune inflammation. Innate immune cells, such as neutrophils, natural killer cells, and mast cells (52), have been revealed to participate in the progress of HF through immune inflammation. For instance, monocytes derived from HF patients have higher secreted cytokines (IL$1 \beta$, IL-6) and chemokines (CCL3, CCL4), and can stimulate $\mathrm{T}$ cell activation (53). Monocyte-derived macrophages have a pro-inflammation role in cardiovascular diseases (49). In addition, several pattern recognition receptors (PRRs), such as NOD-like receptors (NLRs) and Toll-like receptors (TLRs), are mainly expressed on tissue-resident immune cells, can turn on multiple signals to trigger innate immune inflammation. Finally, the activation of the innate immune system can cause the activation of the adaptive immune system by activation and infiltration of B cells and T cells (54).

\section{Inflammatory Cascade Promotes Cardiac Structural Remodeling}

The major cardiac structural remodeling of $\mathrm{HF}$ including cardiac hypertrophy, fibrosis, and extracellular matrix (ECM) remodeling. Systemic inflammation can drive cardiac hypertrophy and fibrosis, and the inflammation is mainly triggered by PRRs (such as NLRP3 and TLR4) mediated innate immune response. The key inflammatory factors in this process are IL-1 $\beta$, IL-6, and NF- $\mathrm{B}$. They can stimulate the release of many other inflammatory cytokines and transcription factors, which may promote cardiac hypertrophy and fibrosis $(55,56)$. The Nod1 receptor signaling pathway can contribute to cardiac hypertrophy (57). The mechanisms of the inflammatory cascade are yet not fully clear. However, it is known that IL- $1 \beta$ is activated by NLRP3 receptive inflammasomes. IL- $1 \beta$ and IL-6 stimulate immune cells ( $\mathrm{T}$ cells, macrophages, and monocytes) to increase the release of IL-17, TNF $\alpha$, and IFN- $\gamma$ (58). These cytokines are signals which may activate immune cell trans differentiation into pro-inflammatory and pro-fibrotic subsets. For instance, Th1/Th2 polarization in T cells toward Th2 has a pro-fibrotic effect. While the CCR2+ monocytes, which express CC-chemokine ligand 2(CCL2) have pro-hypertrophy and pro-fibrotic effects (54). IL-33 is a member of the IL-1 family and ST2 is the receptor of IL-33. IL-33 has an anti-hypertrophic effect, whereas sST2 can competitively inhibit the IL-33/ST2 pathway and promote cardiac hypertrophy and fibrosis (59). Additionally, micro vascular inflammation can stimulate monocyte-derived macrophages to secrete transforming growth factor $\beta$ (TGF- $\beta$ ) which induces pro-fibrosis effects by stimulates the differentiation of fibroblasts into myofibroblasts. Myofibroblasts deposit collagen, and its increase may cause fibrosis (60). Moreover, inflammation may cause pyroptosis and apoptosis, which may also promote cardiac fibrosis (61).

The immune-inflammation mechanism may mediate cardiac ECM remodeling by increases ventricular stiffness $(62,63)$. Ventricular stiffness is a common pathological feature of HFpEF which promotes diastolic dysfunction (64). In systematic inflammation, IL-1 $\beta$ and other cytokines cause increased extracellular deposition of collagen and reduced elasticity of titin, resulting in ventricular stiffness (60).

\section{RECIPROCAL PROMOTION OF COMORBIDITIES AND HF ARE ASSOCIATED WITH METABOLISM AND INFLAMMATION}

Comorbidities and HF interact as both cause and effect, in which metabolism and inflammation are the possible common mechanisms underlying this cyclical relationship. In the following, some common comorbidities, including atrial fibrillation, diabetes, COPD, and obesity, are discussed from the standpoint of epidemiological evidence showing the reciprocal causation associated with underlying common metabolic and inflammatory mechanisms.

\section{Atrial Fibrillation}

Atrial fibrillation (AF) frequently coexists with HFpEF and they share similar risk factors $(65,66)$. In a recent study, more than one-third of the AF patients had HF, and more than half of the HF patients had AF (67). Even subclinical AF was associated with about a 4-fold increase in HF risk (68). On the other hand, $\mathrm{HF}$ promotes $\mathrm{AF}$ via cardiac fibrosis, inflammation, and oxidative stress $(69,70)$. Cardiac resynchronization therapy with a defibrillator can reverse HF remodeling (71).

Metabolism and inflammation are the most consequential underlying mechanisms common to the two diseases. Cardiac energy alterations in HF cause subsequent oxidative stress and inflammatory cascades, and contribute to AF. Mitochondrial $\mathrm{Ca}^{2+}$ handling dysfunction is a shared mechanism in AF and $\mathrm{HF}$, 
in which intracellular calcium leakage happens through oxidative stress-induced hyperphosphorylation of ryanodine receptor (43, 72). The PI3K/AKT may be a shared signaling pathway that regulates cardiac $\mathrm{Ca}^{2+}$ and $\mathrm{Na}^{+}$ion channels (73).

\section{Diabetes Mellitus}

The prevalence of type 2 diabetes mellitus (T2DM) in HF was about 20-50\%, and T2DM may increase mortality due to HF (74). T2DM and HF coexist in about $30-40 \%$ of patients with T2DM (74-76). T1DM (77) is also associated with an increased risk of developing HF.

HF caused by coronary artery disease and hypertension secondary to T2DM is more common in HFrEF (74). Diabetic cardiomyopathy, which refers to HF occurring in the absence of related cardiovascular diseases, is generally believed to be mediated by abnormal mitochondrial calcium handling (78). HFpEF is also associated with insulin resistance-induced ventricular remodeling and mitochondrial dysfunction $(79,80)$. Chronic inflammation caused by excess insulin has also been found to be responsible for diabetic HFpEF (81). Moreover, the byproduct of glycolysis has recently been reported to link diabetes and $\mathrm{HF}$ by post-translational modifications $(82,83)$.

The molecular mechanisms underlying diabetic HF are associated with changes in myocardial substrate metabolism, inflammation, endoplasmic reticulum stress, aberrant insulin signaling, and autophagy (84). For one thing, hyperglycemia and insulin resistance cause excessive ROS production. Furthermore, oxidative stress causes chronic inflammation and mitochondrial metabolic disorders. Several molecular pathways are involved in these processes. ROS activates poly (ADP-ribose) polymerase (PARP) and inhibits the AMPK pathway and decreases mitochondrial biogenesis. These changes would cause disturbed circadian clock synchronization of glucose and FA metabolism. The insulin receptor may activate the PI3K/AKT pathway, which is a major mechanism responsible for insulin resistance induced cardiac dysfunction. Moreover, the activation of $\mathrm{Na}^{+} / \mathrm{H}^{+}$exchange (NHE1/3) can promote HF (85). Finally, the NLRP3 inflammasome is activated in T2DM and triggers NLRP3/ IL-1 $\beta$, IL-6, and IL-18 inflammatory pathways to contribute to cardiac fibrosis (86).

\section{Chronic Obstructive Pulmonary Disease}

About 20\% of unknown HF patients have COPD or asthma (87). Asthma increases HF risk by $80 \%$ (88). COPD is associated with increased risk (89) and worse prognosis of HF (90-92). The prevalence of systolic or diastolic HF in COPD patients ranges from $20 \%$ to $70 \%$ (93). Inhaled corticosteroid/long-acting $\beta 2$ agonists (LABAs) in treating COPD were beneficial to cardiac function (94).

COPD may induce HF through chronic systemic inflammation and pulmonary vascular remodeling (95). In turn, HF aggravates excess ventilation in COPD, and causes dyspnea, and exercise intolerance (96).

\section{Obesity}

The prevalence of obesity in HF was about $40 \%(97,98)$. Obesity increases the risk of HF (99). However, there is a U-shaped relationship between BMI and survival of HF - the so-called "obesity paradox." That is, high BMI is associated with better survival in patients with HF. However, the mortality risk from $\mathrm{HF}$ increased for patients with extremely high BMIs of 45 or greater (98). Furthermore, high waist-to-hip ratios have been associated with increased mortality, suggesting the harmfulness of obesity in HF (100). Abdominal obesity is associated with significantly higher mortality in HFpEF, which may be a better predictor than BMI (101). Abdominal obesity is strongly associated with the circulating level of aldosterone, the main role of which is to regulate salt-water retention. Mineralocorticoid receptor antagonists have recently been discovered as targets for obesityassociated HF (102).

Metabolism and inflammation are involved in the progress of HF in patients with obesity $(103,104)$. Increased leptin, which is reported as the product of the obesity gene, contributes to cardiac remodeling through Leptin-Aldosterone-Neprilysin Axis $(105,106)$. Insulin resistance secondary to obesity can cause altered cardiac energy metabolism and HF (107, 108). Obesity can cause immune-inflammation by activating macrophages, and activate IL-1 $\beta$ and NF- $\kappa$ B pathway (104).

Obesity can suppress BNP levels in HF (109) and causing lower plasma NT-pro-BNP levels (5). Therefore, BNP may not reflect the HF severity accurately in obese patients $(110,111)$. BNP enacts cardiac protection via multiple actions, such as suppressing RAAS activation and regulating sodium metabolism. An insufficient BNP level may promote HF progression (112).

\section{Cancers}

Cancers and HF are often coexisting in patients with cancers, they share several common pathophysiological mechanisms and causes, such as angiogenesis, clonal haematopoiesis, and sarcopenia (113-115). Aging may cause somatic mutations of genes (typically DNMT3A and TET2) in hematopoietic stem cells, which promote peripheral blood leukocytes release proinflammatory factors such as IL-1 $\beta$ and IL-6. This phenomenon is called clonal hematopoiesis of indeterminate potential (CHIP), which is a risk factor of cardiovascular diseases and cancer (116). Sarcopenia is a common complication in advanced stage cancer, which may promote HF through muscle wasting and thinning of the ventricular wall, (115).

Cardio toxicity is a major risk factor for HF. It reportedly accounts for $45 \%$ of all drug withdrawals (117). Mitochondrial dysfunction is the major pathophysiologic mechanism of druginduced cardio toxicity $(117,118)$. In most times a drug with cardio toxicity would not be used in clinical. However, antitumor drugs with cardio toxicity are common when weighing the pros and cons because of the therapeutic effect (119). For instance, aromatase inhibitors have become the preferred treatment for estrogen receptor-positive breast cancer, which targets the cytochrome P450 enzyme, but it is associated with a significantly increased risk of HF (120). Anthracyclines such as doxorubicin (121) and epirubicin (122) are commonly used for breast cancers, lymphoma (123), and a variety of other cancers, but their usage is limited by cardio toxicity. Trastuzumab, another breast cancer drug, is also associated with increased HF risk (124). The proposed biological mechanisms underlying 
anthracycline cardio toxicity are mitochondrial dysfunction, mitochondrial iron overload, oxidative stress, inflammation, and impaired autophagy (125).

\section{LINK BETWEEN HEART FAILURE AND COMORBIDITIES}

Common risk factors such as aging, hyperglycemia, and lifestyle are the cause of $\mathrm{HF}$ and comorbidities. The underlying mechanisms of these factors are associated with common metabolic or inflammatory pathways. In this review, the major pathways were identified through gene enrichment analysis. Further, the common therapy drug targets have also be summarized by analyzing the disease-gene network. This review will be helpful for selecting the therapeutic strategy.

\section{Major Shared Risk Factors of HF and Comorbidities Are Associated With Metabolism and Inflammation}

Epidemiologic evidence has found many risk factors for cardiovascular diseases, including chronic conditions or diseases (aging, hyperlipidemia, hypertension, hypoxaemia, and metabolic syndrome), and lifestyles (dietary and sleeping patterns, smoking, and drinking (126-128). Unhealthy lifestyles may contribute to HF by dysregulated innate immunity and chronic inflammation (129). These factors are also risk factors for many comorbidities (130) and share similar mechanisms, which are associated with metabolism and inflammation.

Aging is one of the major risk factors for developing multi morbidity and HFpEF, and both multi morbidity and HFpEF are unmet needs in the therapy of HF (131-133). The main underlying mechanisms of cardiovascular aging are associated with mitochondrial metabolism $(134,135)$, chronic inflammation (136), autophagy (137), and oxidative stress (138).

Physical inactivity (sedentary behavior), is a risk factor of multi morbidity (139), it causes chronic subclinical myocardial injury detectable with high-sensitivity cardiac troponin and increases HF risk (140). Meta-analysis showed exercise is beneficial for people with multi morbidity (141). It can regulate mitochondrial remodeling (142), and also causes physiologic remodeling which increases cardiorespiratory fitness (143). It is improved cardiorespiratory fitness that is the physiopathological link between obesity, exercise, and $\operatorname{HF}(93,94)$, primarily by increases the cardiac compensatory capacity (17). Furthermore, exercise has direct anti-inflammatory effects by inhibition of TNF- $\alpha$ and IL-1 $\beta$, and may attenuate insulin resistance (144).

Metabolic syndrome, mainly charactered by hyperlipidemia and hypertension, shared similar mechanisms to that of diabetes and obesity, such as insulin resistance and macrophage induced inflammation, which have already been discussed (104). Taken together, metabolism and chronic inflammation are the major mechanisms underlying the major shared risk factors between $\mathrm{HF}$ and comorbidities.

\section{Common Molecular Pathways Analysis}

Although many metabolism and inflammation mechanisms have been reviewed previously, which pathways are most important remains unclear. To conduct an unbiased analysis of the key shared biological pathways in HF and comorbidities, we performed enrichment analysis on target genes of HF and some comorbidities of high prevalence in the database. The Target Validation platform (https://www.targetvalidation.org/) contains disease target genes from Genome-Wide Association Studies (GWAS), drug targets from the EMBL-EBI ChEMBL database, EMBL-EBI RNA expression data, and text mining of literature. First, we retrieved all the targets of $\mathrm{HF}$ and several comorbidities (diabetes mellitus, obesity, COPD, chronic kidney disease, and OSA) in the Target Validation platform (accessed on March 22, 2021) and intersected the disease targets as shown in the Venn diagram (Figure 3A). Five comorbidities (diabetes mellitus, obesity, COPD, CKD, and obstructive sleep apnea) were selected for analysis because these represent the most highly prevalent comorbidities (The major enriched pathways did not change but the Venn diagram and the latter network plot would be more complex and less understandable when adding other common comorbidities such as atrial fibrillation and depression into the analysis). There were 299 common targets associated with all the four diseases, and 1,051 common targets were shared by HF and at least four of the comorbidities. Gene Ontology and KEGG enrichment analysis was performed on 1,051 semi-common targets with the $\mathrm{R}$ (version 3.6.0) package cluster Profiler (version 3.14.3). The activation of metabolic and inflammatory pathways may require the expression level change or activation of a group of enzymes, cytokines, or proteins regulated by common transcription factors. To identify key transcription factors, transcription factors enrichment analysis was performed using Meta scape website tools (http://metascape.org) (145) with TRRUST (Transcriptional Regulatory Relationships Unraveled by Sentence-based Text mining) database (146) and the figure was plotted with ggplot2 (version 3.3.3).

Some known factors which play a crucial role in HF, such as the NADPH oxidase (147), and sulfur compound binding (148), and growth factor activity (149) were enriched in the Geno ontology enrich analysis (Figure 3B).

The enriched pathways are mainly associated with metabolism and inflammation. Some significantly enriched pathways not shown in the figure are also analyzed. According to their role in $\mathrm{HF}$, most of the significantly enriched pathways can be classified into one or more of the following categories: (1) Energy metabolic associated pathways. The PI3K/Akt pathway regulates both metabolic and structural remodeling. The PI3K/AKT pathway is associated with AF (150), COPD (151), HF (152), and multi morbidity (131). The PI3K/AKT pathway regulates cardiac metabolism both in pathological remodeling in HF (143), and it also regulates heart growth (149). (2) Structure remodeling associated pathways. The MAPK pathway is the key pathway activated in response to ischemia and has a critical role in cardiac hypertrophy. Moreover, the MAPK pathway may be involved in the interplay of mitochondrial energy metabolism and systemic inflammation (57). The Hypoxia-Inducible Factor 


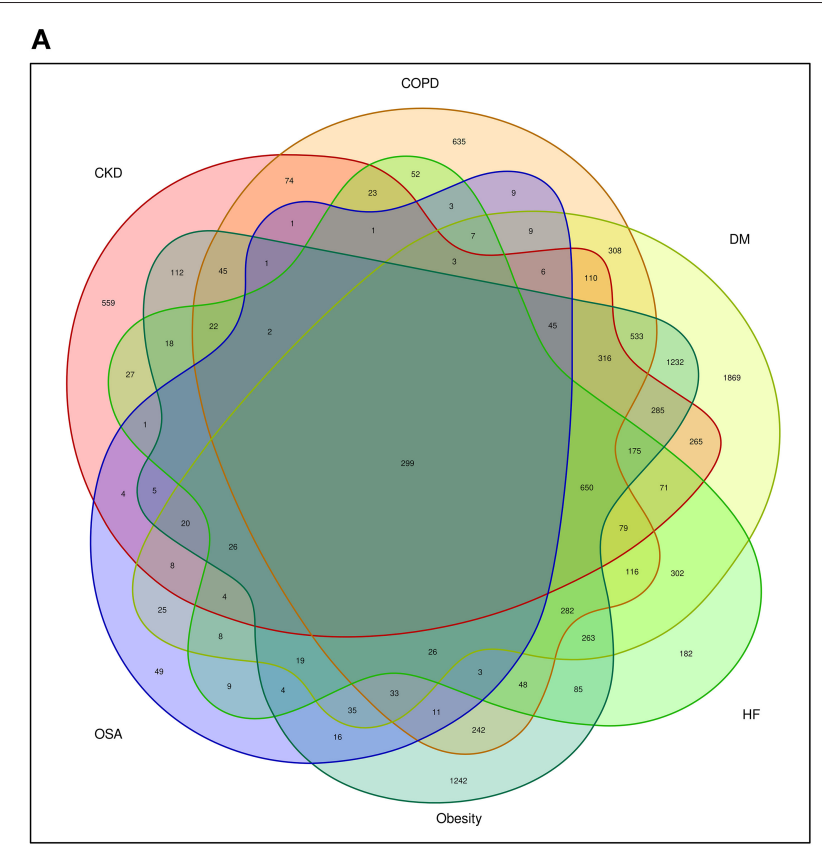

C

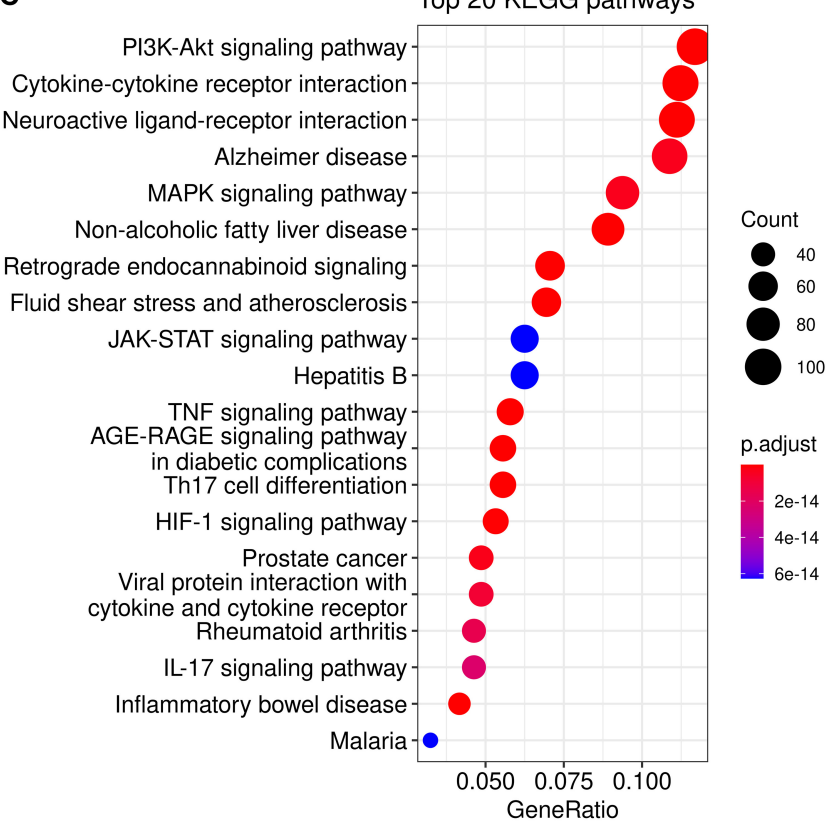

B

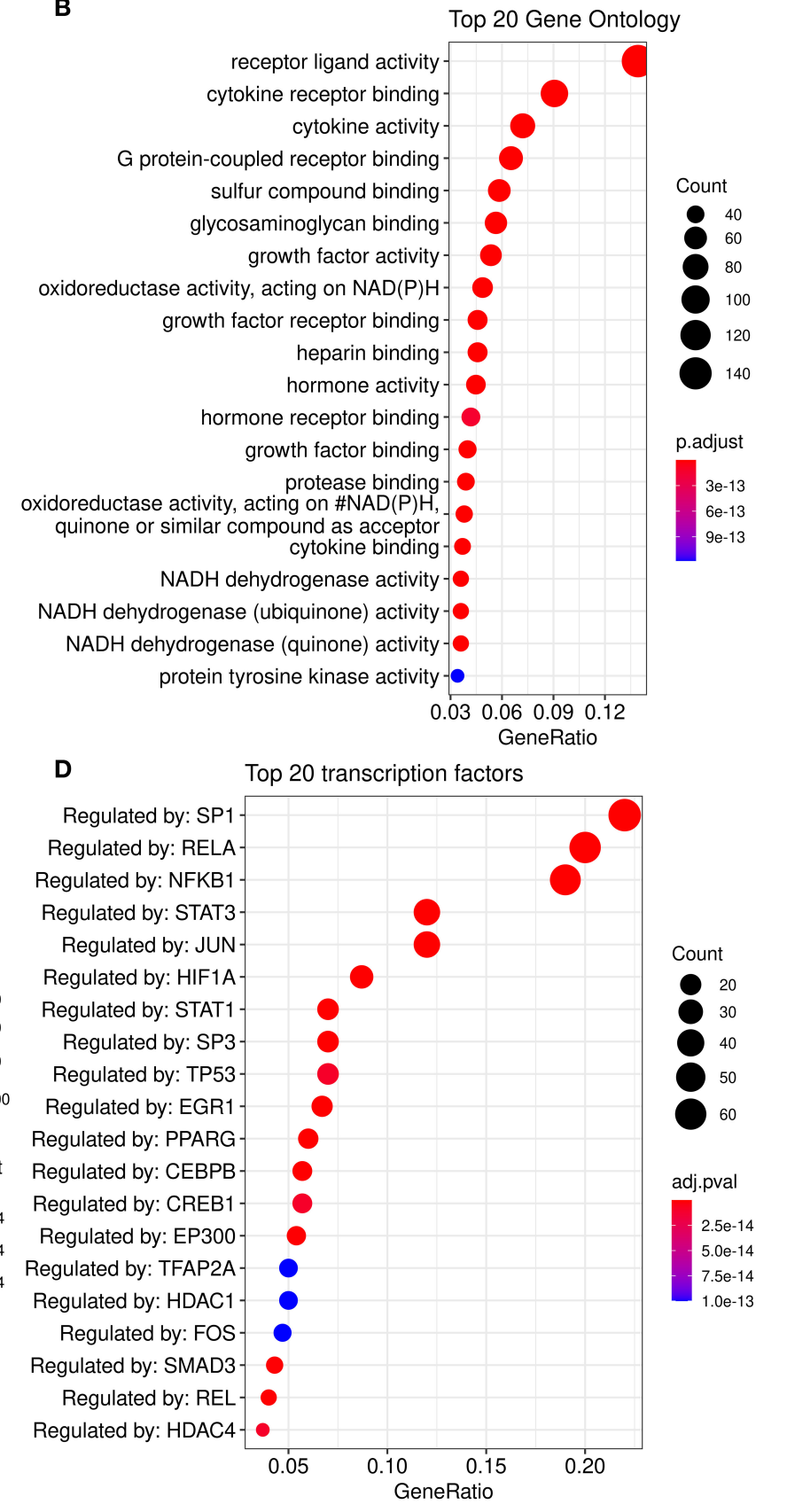

FIGURE 3 | Analysis of common genes and pathways in comorbidities and HF. (A): Venn diagram of common genes between comorbidities and HF; (B): Dot plot of top 20 enriched Gene Ontology biological processes enriched for common genes between HF and comorbidities; (C): Dot plot of top 20 enriched KEGG (Kyoto Encyclopedia of Genes and Genomes) pathways for common genes between HF and comorbidities; (D):Dot plot of top 20 enriched transcription factors from TRRUST(Transcriptional Regulatory Relationships Unraveled by Sentence-based Text mining) database.

1 (HIF-1) pathway can regulate glucose metabolism and is adaptively activated in response to hypoxia conditions and can promote cardiac hypertrophy. HIF-1 can activate the glycation end products (AGE) advanced glycation end products (RAGE) signaling. The AGE-RAGE signaling pathway is associated with some comorbidities of HF such as OSA and diabetes $(153,154)$.
Insulin-like growth factor (IGF) signaling is activated in $\mathrm{HF}$ and promotes cardiac hypertrophy (155, 156); (3) Cardiac systolic and diastolic functions associated pathways. Such as the CaMKII pathway (157), The G protein-coupled receptor (GPCR) signaling pathway is a known drug target of HF, these drugs include $\beta$-adrenergic receptor and angiotensin II receptor 
antagonists (158). (4) Inflammatory pathways, majorly include the Cytokine-cytokine receptor interaction, TNF signaling, IL-17 signaling, and Toll-like receptor pathways (Figure 3C). Additionally, the clonal hematopoiesis pathway is a risk factor of $\mathrm{HF}$ enriched in the analysis and may be related to immune inflammation $(53,159)$. (5) Other structural remodeling in addition to hypertrophy, such as fibrosis and amyloidosis. The activation of inflammatory pathways can activate the TGF- $\beta$ pathway and promote fibrosis. Alzheimer's disease is also enriched. Alzheimer's disease is major characterized by amyloidosis, and senile amyloidosis may be an overlooked causal mechanism of HFpEF $(60,66)$. The PI3K/AKT/GSK3 $\beta$ pathway is proposed as the link between diabetes and Alzheimer's disease (160).

The PI3K/AKT pathway is most significant in the pathway enrich analysis and is a key pathway in cardiac remodeling. Cardiac remodeling is a key biological process that contributes to the progression of HF. Some drugs, such as calcium antagonists and renin inhibitors, may alleviate hypertension and improve contraction function of HF, they did not improve remodeling, and therefore did not improve the prognosis of HF (161). Some downstream signaling pathways, such as $\mathrm{PI} 3 \mathrm{~K} / \mathrm{AKT} / \mathrm{eNOS}$ have a cardio protective role, and the activation of this pathway may be the mechanism of some cardiovascular drugs such as statins (162). PI3K/AKT pathway activation is a shared mechanism in physiological and pathological cardiac hypertrophy, and physiological hypertrophy may enhance cardiac systolic and diastolic function (143). However, in pathological conditions, such as HF, long-term sustained activation of PI3K/AKT pathway in HF promotes excessive cardiac growth, mitochondrial dysfunction, ROS production, and impaired $\mathrm{Ca}^{+}$handling (163). Activation of PI3K/AKT pathway is a common mechanism in many chronic diseases, such as cardiovascular disease, metabolic diseases, COPD, and cancers (131). It has been reported improved HF syndrome with no substantial side effects when using PI3K/AKT inhibitors as a treatment of PIK3CA-related overgrowth syndrome (164). Therefore, PI3K/AKT inhibitors may be a promising treatment for $\mathrm{HF}$ and comorbidities. However, because the activation of $\mathrm{PI} 3 \mathrm{~K} / \mathrm{AKT}$ pathway is essential for many cellular processes such as cell growth, proliferation, and migration, targeting PI3K/AKT pathway may have side effects, finding a more specific target of $\mathrm{HF}$ and comorbidities related to PI3K/AKT pathway may be a better treatment choice.

\section{Common Mechanistic Pathways in Heart Failure and Comorbidities}

Together with a review of the literature into account, the main shared mechanisms of HF-induced comorbidities can be summarized (Figure 4) and elucidated. The mechanism of how comorbidities promote HF may be clarified similarly by the shared mechanisms.

The metabolic mechanisms of HF promote comorbidities are associated with mitochondria injury, oxidative stress, insulin resistance, and hypoxia. $\mathrm{HF}$ and risk factors induce altered cardiac energy metabolism. Cardiac energy metabolic

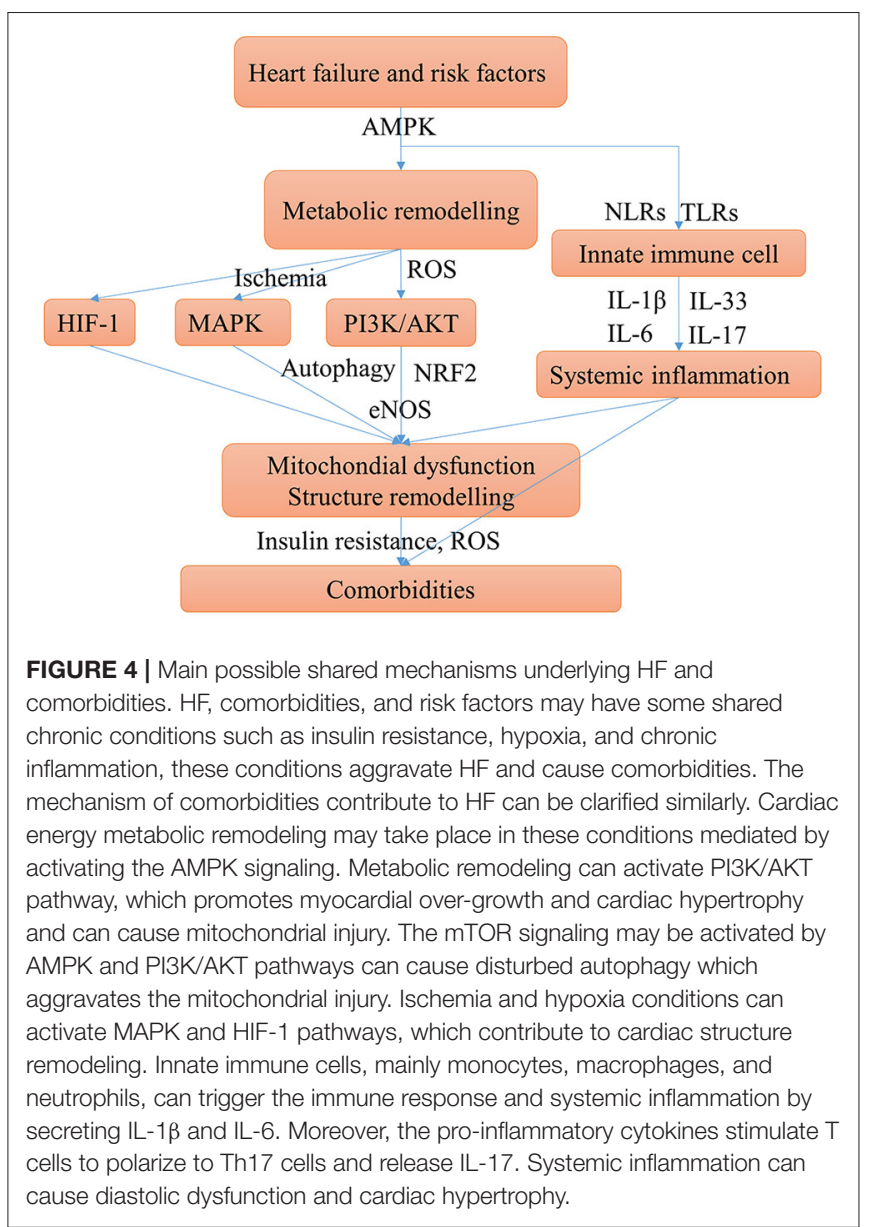

remodeling causes oxidative stress through NAD (P) H oxidasederived ROS (165). Oxidative stress can trigger mitochondrial injury and inflammation. As such, antioxidants have been a therapeutic strategy for cardiovascular diseases (166). Oxidative stress, mitochondrial dysfunction, and chronic inflammation were the major mechanisms of multi morbidity in the elderly (131). There is a consensus that mitochondrial impairment is key to cardiac dysfunction in HF (167). Mitochondria injury can cause cardiac remodeling, such as hypertrophy and fibrosis (168). In addition, mitochondrial biogenesis dysfunction play important roles in multi morbidity such as diabetes (169), obesity (170), lung diseases $(171,172)$, depression (173), sarcopenia (142), iron deficiency $(148,174)$, fatty liver disease (175), obstructive sleep apnea (176), and diabetic kidney disease (177). Mitochondria injury is commonly induced by oxidative stress or inflammation mediated by the PI3K/AKT/eNOS, PI3K/AKT/mTOR, AMPK/mTOR pathway (178), or the MAPK signaling pathway (179). Mitochondria autophagy, also called mitophagy, is a cellular process in which impaired mitochondria are destroyed to protect eukaryotic cells from mitochondrial injury. Autophagy has a protective role for HF and comorbidities, and may be injured by the activation of mTOR pathway (180). Insulin resistance plays an important role in the 
pathological processes of $\mathrm{HF}$, and is also strongly associated with diabetes (181), as well as obesity in which is associated with the phosphorylation of PPAR $\gamma$ (182). Insulin resistance was associated with the worse outcomes in patients with HF and diabetes (183). Hypoxia is a common chronic condition in many comorbidities such as COPD and anemia, and the related HIF-1 pathway may have an important role in the progression of obesity and hypertension (104).

Chronic systemic inflammation associated with HF is mainly triggered by innate immune cells (monocyte, macrophage, and neutrophils). The major pro-inflammatory cytokines including IL-1 $\beta$, IL-6, IL-8, IL-17, IL-18, and TNA- $\alpha(49,184,185)$. Apart from their role in HF, IL- $1 \beta$ and IL- 6 are key pro-inflammatory factors in many diseases, like COPD (186), diabetes (187), kidney disease (188), sarcopenia, obesity, and HF (189), and the cytokine storm in COVID-19 (190). A recent study on HFpEF supported that systemic inflammation may be the association between comorbidity and HF (191). The IL- $1 \beta$ and IL-18 signaling pathways may be novel drug targets for HFpEF, which are important in the mitochondria-inflammation circuit (192).

The alteration of pathways is often regulated by transcription factors as switches. Many common transcription factors have been found including SP-1, RELA, NF-кB, STAT3, HIF- $1 \alpha$, $\operatorname{PPAR} \gamma, c-F O S$, and c-JUN (Figure 3D) and together with a review of the literature, the transcription factors network in HF and comorbidities are briefly summarized as follows: (1) Regulation of inflammation. NF- $\mathrm{B}$ is the key transcription factor in inflammation. Both RELA and NFKB1 are genes of NF- $\kappa \mathrm{B}$ subunit. NF- $\kappa \mathrm{B}$ regulates inflammation initiated $\mathrm{Ca}^{2+} /$ Calmodulin-dependent cardiac remodeling (193). STAT3 is a predicted target regulated by $\mathrm{NF}-\kappa \mathrm{B}$ in Figure $3 \mathrm{D}$. The activation of NF- $\kappa \mathrm{B}$ and STAT3 is required for the expression of multiple inflammatory cytokines including IL-1 $\beta$ (194), TNA- $\alpha$ (195) and IL-6. The c-FOS and c-JUN are family of AP-1, which regulate the MAPK pathway, and can be inhibited by SIRT3 (196). EGR1 and c-FOS are also associated with the release of IL-1 $\beta$ (197). SP-1 can regulate immune responses, but it is a non-specific transcription factor involved in many other cellular processes and indicates transcriptional activation; (2) Regulation of metabolism. The activation of PPAR $\gamma$ is essential for the FAO process (18). The sirtuin family members SIRT1, SIRT2, and SIRT3 are important transcription factors in cardiac energy metabolism and have similar roles. SIRT3 regulates ATP production (198). SIRT2 and PPAR $\alpha$ regulate glycose metabolism by the AMPK pathway (199), SIRT1 and NRF2 regulate energy metabolism and mitochondrial biogenesis (200).

\section{Common Therapeutic Drug Targets}

Common pathways indicate common targets, which are the basis for drug repurposing. Network analysis is often used in the repurposing of drugs (201). The known drug targets of $\mathrm{HF}$, diabetes mellitus, COPD, CKD, sleep apnea, and obesity were retrieved from the Target Validation Platform (targetvalidation.org). We constructed a disease-target network in Cytoscape 3.8.0 (202). Some representative drugs were randomly chosen and listed in Figure $\mathbf{5}$ to provide an example.
The drugs range from old drugs like metformin to relatively new ones in HF treatment, like SGLT2 inhibitors. However, network analysis has some limitations and should be interpreted combined with literature review. For one thing, it is based on the database, and some drugs in the database had been investigated in HF clinical trials but have no effect. Some drugs such as calcium channel blockers could not treat HF. For another, a drug associated with multiple targets might be non-specific and does not necessarily have better effects. For instance, doxorubicin inhibits both Top2a and Top2b, inhibiting Top2a have an anti-cancer effect while inhibiting Top2b have a cardiac side effect (125). Anti-inflammatory therapy with Canakinumab (203) in clinical trials which target IL-1 $\beta$ can reduce the mortality of $\mathrm{HF}$ patients. IL- $1 \beta$ is an important inflammatory cytokine associated with many comorbidities. Canakinumab can improve the prognosis of cardiovascular outcomes in patients with CKD (204). However, Canakinumab could not reduce the incidence of new-onset diabetes (205), which suggests the role of inflammation in diabetes might be less important. Anakinra, a recombinant IL-1 receptor antagonist, is another drug targets IL- $1 \beta$, it is under phase III clinical trial in HF and has a therapeutic effect (206). In summary, IL-1 $\beta$ inhibitors/antagonists are promising drugs for $\mathrm{HF}$ and comorbidities.

Diabetes drugs are a good example of drug repurposing applied in HF. Some therapy of diabetes may increase the risk of HF such as insulin (183), whereas some drugs such as metformin, sulphonylureas, and gliptins either alone or in combination, could significantly reduce the risk of HF (207). The SGLT2 inhibitors are originally designed for diabetes, which targets the SLC5A2 gene, and have shown benefit for HF, regardless of whether comorbid with diabetes or not (208, 209). In a clinical trial, there were unexpected excellent risk reductions in hospitalization for $\mathrm{HF}$ and all-cause mortality with the use of the SGLT2 inhibitor, empagliflozin (210). The benefit of empagliflozin could not be explained by the effects of classical inhibitors, such as natriuresis or neurohormonal mechanisms. It has been speculated that the shift in cardiac energy substrate may play a major role in the cardiorenal benefits of empagliflozin; that is, a shift from using glucose and fat to ketone bodies (211). Linagliptin, a DPP-4 inhibitor designed to treat diabetes, can also be used to treat HF (212, 213). Metformin affects many targets that are associated with oxidative phosphorylation in mitochondria (214), such as MTND5 and NDUFB7, and has been reported to have therapeutic effects on $\mathrm{HF}$ and comorbidities. Metformin is an indirect AMPK pathway activator, and also increases glucose transport and catabolism by increasing the residence time of GLUT4. AMPK agonists are promising HF therapy drugs, which consist of direct activators, such as A-769662 (a preclinical drug), or indirect activators, such as $5^{\prime}$-aminoimidazole-4-carboxyamideribonucleoside $(22,215)$.

Although many anti-tumor drugs have cardio toxicity, network analysis of shared pathways and targets enables us to find drugs beneficial for both diseases. For example, PI3K/Akt/mTOR pathway is a shared pathway in cancers and HF, drugs targeting the mTOR pathway, such as rapamycin, are novel potential 


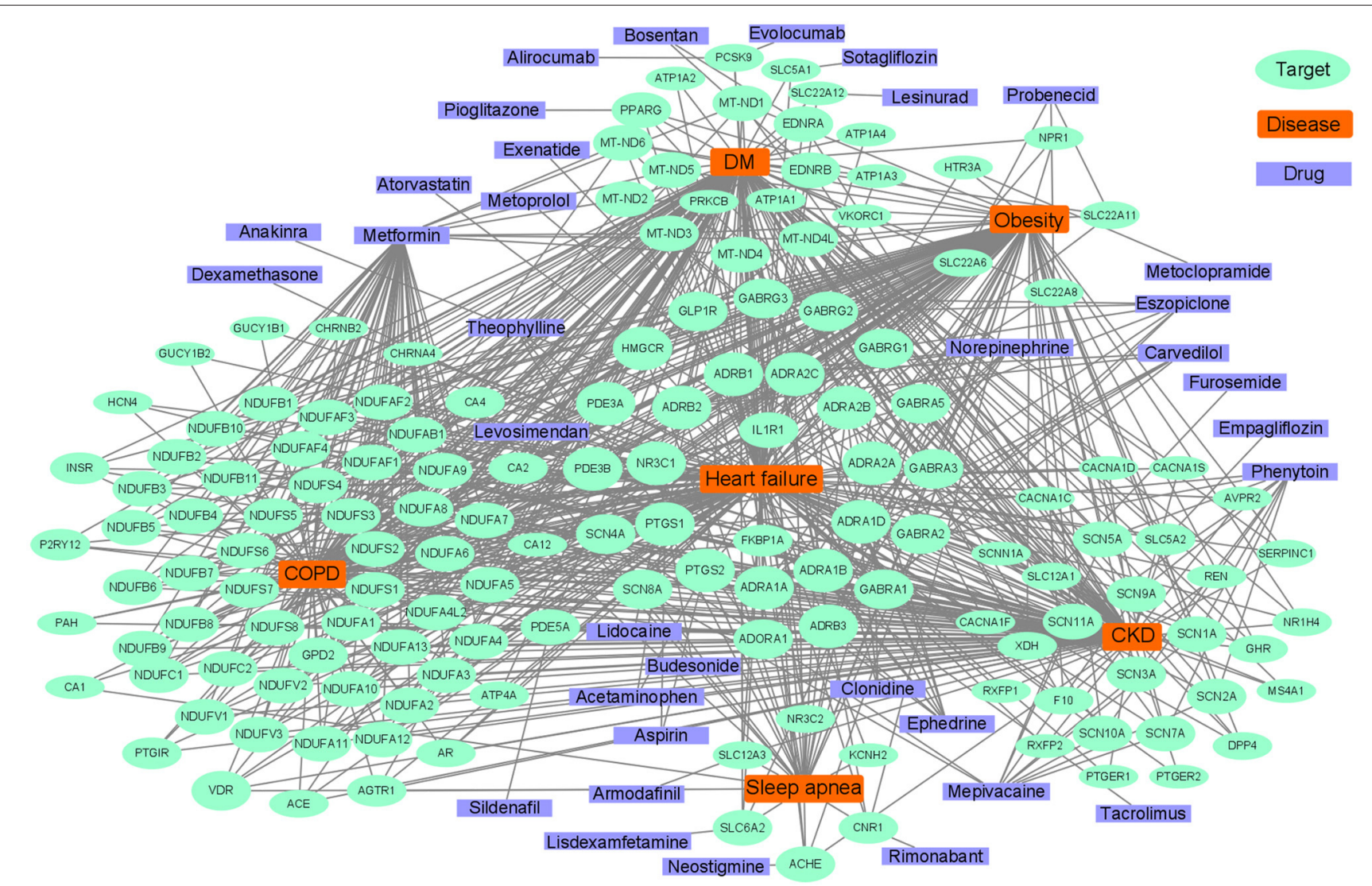

FIGURE 5 | Abridged common drug target network of heart failure and comorbidities.

drugs for $\mathrm{HF}$ which can reduce cardiac remodeling and HF (119).

There are some genes of the phosphodiesterase family, such as PDE5A, PDE3A, and PDE3B. PDE5 inhibitors (such as Sildenafil) regulates the nitric oxide synthases and hydrogen sulfide (H2S) generation, and may attenuate ROS induced mitochondrial dysfunction through the AMPK pathway (216). However, side effects largely limit its clinical application, probably because PDE5 is involved in a variety of biological processes not specific to $\mathrm{HF}$.

Beyond known drug targets, some targets may have similar functions as they belong to the same protein family. Similar to SLC5A2, SLC25A51 is a member of the solute carrier family, and has been recently found to be a mitochondrial $\mathrm{NAD}+$ transporter (217) and may perhaps serve as a new drug target.

\section{Links Between Heart Failure Phenotypes and Comorbidity}

Multi morbidity and HFpEF are both unmet needs in HF therapy. Comorbidities exist in both HFpEF and HFrEF, but the prevalence of most comorbidities is higher in the HFpEF than reduced ejection fraction $(\mathrm{HFrEF})(6,218)$, indicating a strong association between HFpEF and comorbidities (6). The prevalence of preserved ejection fraction $\mathrm{HF}$ (HFpEF) is rising, and mortality remains high because of the absence of effective therapies $(60,219)$, which gives rise to the urgent need for drug discovery targeting HFpEF. Although HFpEF has a better ejection fraction than HFrEF, the mortalities are similar, and the higher frequency of morbidities in HFpEF than HFrEF may explain the phenomena (220). The risk factors and incidence of comorbidities are different, therefore the pathways, therapeutic targets, and drugs between the subclasses of HF were different. COPD and OSA are associated with increased HFpEF disease risk and adversely impact cardiovascular disease outcomes, in which chronic inflammation and oxidative stress are responsible for the association. Therefore, drugs like statin and/or antioxidants may be beneficial $(221,222)$. Compared with HFrEF, there are more hypertension and fewer coronary diseases in HFpEF $(218,223)$. Atrial fibrillation is associated with significantly increased mortality (224), and AF is more frequently in HFpEF than HFrEF (218). Because multi morbidity is more frequent in $\mathrm{HFpEF}$, targeting the common pathways between comorbidities may be a potential novel therapy for HFpEF.

Expression levels of biomarkers is also different between systolic and diastolic HF. The BNP level is lower in HFpEF 
(225) and NT-proBNP/BNP-guided therapy was reportedly only beneficial in HFrEF because comorbidities may influence BNP level and provide misleading information (226).

\section{CONCLUSION AND FUTURE PERSPECTIVES}

In this review, we concluded the pathology and molecular mechanisms of comorbidities of HF. Metabolism remodeling and chronic inflammation are responsible for the major underlying pathophysiologic links between $\mathrm{HF}$ and comorbidities. Mitochondrial metabolism is expected to play a central role, but no drugs specifically conceived to modulate mitochondrial functions are currently available (227). The therapy for comorbidities of $\mathrm{HF}$ is increasingly becoming challenging. The common metabolic and inflammatory mechanisms may provide promising possible therapeutic targets for both HF and comorbidities, which may be useful for both old drug repurposing and the discovery of new drugs.

\section{REFERENCES}

1. Bloom MW, Greenberg B, Jaarsma T, Januzzi JL, Lam CSP, Maggioni AP, et al. Heart failure with reduced ejection fraction. Nat Rev Dis Primers. (2017) 3:17058. doi: 10.1038/nrdp.2017.58

2. Conrad N, Judge A, Tran J, Mohseni H, Hedgecott D, Crespillo AP, et al. Temporal trends and patterns in heart failure incidence: a population-based study of 4 million individuals. Lancet. (2018) 391:57280. doi: 10.1016/S0140-6736(17)32520-5

3. Hao G, Wang X, Chen Z, Zhang L, Zhang Y, Wei B, et al. Prevalence of heart failure and left ventricular dysfunction in China: the China hypertension survey, 2012-2015. Eur J Heart Failure. (2019) 21:132937. doi: 10.1002/ejhf.1629

4. Ziaeian B, Fonarow GC. Epidemiology and aetiology of heart failure. Nat Rev Cardiol. (2016) 13:368-78. doi: 10.1038/nrcardio.2016.25

5. Nadrowski P, Chudek J, Grodzicki T, Mossakowska M, Skrzypek M, Wiecek A, et al. Plasma level of N-terminal pro brain natriuretic peptide (NTproBNP) in elderly population in poland-the polsenior study. Exp Gerontol. (2013) 48:852-7. doi: 10.1016/j.exger.2013.05.060

6. Triposkiadis F, Giamouzis G, Parissis J, Starling RC, Boudoulas H, Skoularigis J, et al. Reframing the association and significance of co-morbidities in heart failure. Eur J Heart Failure. (2016) 18:74458. doi: 10.1002/ejhf.600

7. von Haehling S. Co-morbidities in heart failure beginning to sprout-and no end in sight? Eur J Heart Failure. (2017) 19:1566-8. doi: 10.1002/ ejhf.1098

8. Khan MS, Samman Tahhan A, Vaduganathan M, Greene SJ, Alrohaibani A, Anker SD, et al. Trends in prevalence of comorbidities in heart failure clinical trials. Eur J Heart Failure. (2020) 22:1032-42. doi: 10.1002/ejhf.1818

9. White JR, Chang CC, So-Armah KA, Stewart JC, Gupta SK, Butt AA, et al. Depression and human immunodeficiency virus infection are risk factors for incident heart failure among veterans: veterans aging cohort study. Circulation. (2015) 132:1630-8. doi: 10.1161/CIRCULATIONAHA.114.014443

10. Yusuf S, Joseph P, Rangarajan S, Islam S, Mente A, Hystad P, et al. Modifiable risk factors, cardiovascular disease, and mortality in 155 722 individuals from 21 high-income, middle-income, and low-income countries (PURE): a prospective cohort study. Lancet. (2020) 395:795808. doi: 10.1016/S0140-6736(19)32008-2

\section{AUTHOR CONTRIBUTIONS}

ZL performed an extensive literature review, drafted the manuscript, and prepared figures. JW and $\mathrm{HZ}$ proposed the subject of the review, critically revised, and edited the manuscript. All authors contributed to the article and approved the submitted version.

\section{FUNDING}

This study was financially supported by the National Key Research and Development Program of China Grants 2018YFC1315103 (to HZ), 2019YFA0801700, 2019YFA0801800 (to JW); National Natural Science Foundation of China Grants 81800359 (to HZ) and 81622008, 81470579 (to JW); Chinese Academy of Medical Sciences Innovation Fund for Medical Sciences (2016-I2M-1-006) (to JW); Peking Union Medical College Youth Fund/the Fundamental Research Funds for the Central University (3332016048) (to HZ); and Thousand Young Talents Program of China (to JW).

11. Sbolli M, Fiuzat M, Cani D, O'Connor CM. Depression and heart failure: the lonely comorbidity. Eur J Heart Failure. (2020) 22:2007-17. doi: 10.1002/ejhf.1865

12. Drager LF, McEvoy RD, Barbe F, Lorenzi-Filho G, Redline S. Sleep apnea and cardiovascular disease: lessons from recent trials and need for team science. Circulation. (2017) 136:184050. doi: 10.1161/CIRCULATIONAHA.117.029400

13. Takada S, Sabe H, Kinugawa S. Abnormalities of skeletal muscle, adipocyte tissue, and lipid metabolism in heart failure: practical therapeutic targets. Front Cardiovasc Med. (2020) 7:79. doi: 10.3389/fcvm.2020. 00079

14. Suzuki K, Claggett B, Minamisawa M, Packer M, Zile MR, Rouleau J, et al. Liver function and prognosis, and influence of sacubitril/valsartan in patients with heart failure with reduced ejection fraction. Eur J Heart Failure. (2020) 22:1662-71. doi: 10.1016/S0735-1097(20)31427-3

15. Tromp J, Tay WT, Ouwerkerk W, Teng TK, Yap J, MacDonald MR, et al. Multimorbidity in patients with heart failure from 11 asian regions: a prospective cohort study using the ASIAN-HF registry. PLoS Med. (2018) 15:e1002541. doi: 10.1371/journal.pmed.1002541

16. Neubauer S. The failing heart-an engine out of fuel. N Engl J Med. (2007) 356:1140-51. doi: 10.1056/NEJMra063052

17. Stanley WC, Recchia FA, Lopaschuk GD. Myocardial substrate metabolism in the normal and failing heart. Physiol Rev. (2005) 85:1093-129. doi: 10.1152/physrev.00006. 2004

18. Bertero E, Maack C. Metabolic remodelling in heart failure. Nat Rev Cardiol. (2018) 15:457-70. doi: 10.1038/s41569-018-0044-6

19. Nickel A, Löffler J, Maack C. Myocardial energetics in heart failure. Basic Res Cardiol. (2013) 108:358. doi: 10.1007/s00395-013-0358-9

20. Gibb AA, Hill BG. Metabolic coordination of physiological and pathological cardiac remodeling. Circ Res. (2018) 123:10728. doi: 10.1161/CIRCRESAHA.118.312017

21. Noordali H, Loudon BL, Frenneaux MP, Madhani M. Cardiac metabolism - a promising therapeutic target for heart failure. Pharmacol Ther. (2018) 182:95-114. doi: 10.1016/j.pharmthera.2017.08.001

22. Arumugam S, Sreedhar R, Thandavarayan RA, Karuppagounder V, Watanabe K. Targeting fatty acid metabolism in heart failure: is it a suitable therapeutic approach? Drug discovery today. (2016) 21:10038. doi: 10.1016/j.drudis.2016.02.010 
23. Birkenfeld AL, Jordan J, Dworak M, Merkel T, Burnstock G. Myocardial metabolism in heart failure: purinergic signalling and other metabolic concepts. Pharmacol Ther. (2019) 194:13244. doi: 10.1016/j.pharmthera.2018.08.015

24. Nguyen TD, Schulze PC. Lipid in the midst of metabolic remodeling therapeutic implications for the failing heart. Adv Drug Deliv Rev. (2020) 159:120-32. doi: 10.1016/j.addr.2020.08.004

25. Carley AN, Lewandowski ED. Triacylglycerol turnover in the failing heart. Biochim Bio Acta. (2016) 1861:1492-9. doi: 10.1016/j.bbalip.2016.03.012

26. Son NH, Yu S, Tuinei J, Arai K, Hamai H, Homma S, et al. PPAR $\gamma$ induced cardiolipotoxicity in mice is ameliorated by PPAR $\alpha$ deficiency despite increases in fatty acid oxidation. J Clin Invest. (2010) 120:344354. doi: 10.1172/JCI40905

27. Kohlhaas M, Nickel AG, Maack C. Mitochondrial energetics and calcium coupling in the heart. J Physiol. (2017) 595:3753-63. doi: 10.1113/JP273609

28. Murashige D, Jang C, Neinast M, Edwards JJ, Cowan A, Hyman MC, et al. Comprehensive quantification of fuel use by the failing and nonfailing human heart. Science. (2020) 370:364-8. doi: 10.1126/science.abc8861

29. Selvaraj S, Kelly DP, Margulies KB. Implications of altered ketone metabolism and therapeutic ketosis in heart failure. Circulation. (2020) 141:180012. doi: 10.1161/CIRCULATIONAHA.119.045033

30. D’Antona G, Ragni M, Cardile A, Tedesco L, Dossena M, Bruttini F, et al. Branched-chain amino acid supplementation promotes survival and supports cardiac and skeletal muscle mitochondrial biogenesis in middle-aged mice. Cell Metab. (2010) 12:362-72. doi: 10.1016/j.cmet.2010. 08.016

31. Toneto AT, Ferreira Ramos LA, Salomão EM, Tomasin R, Aereas MA, Gomes-Marcondes MC. Nutritional leucine supplementation attenuates cardiac failure in tumour-bearing cachectic animals. J Cach Sarco Muscle. (2016) 7:577-86. doi: 10.1002/jcsm.12100

32. Fidale TM, Antunes HKM, Alex Dos Santos L, Rodrigues de Souza F, Deconte SR, Borges Rosa de Moura F, et al. Increased dietary leucine reduces doxorubicin-associated cardiac dysfunction in rats. Front Physiol. (2017) 8:1042. doi: 10.3389/fphys.2017.01042

33. Sun $H$, Wang $Y$. Branched chain amino acid metabolic reprogramming in heart failure. Biochim Bio Acta. (2016) 1862:2270-5. doi: 10.1016/j.bbadis.2016.09.009

34. Lynch CJ, Adams SH. Branched-chain amino acids in metabolic signalling and insulin resistance. Nat Rev Endocrinol. (2014) 10:723-36. doi: 10.1038/nrendo.2014.171

35. Uddin GM, Zhang L, Shah S, Fukushima A, Wagg CS, Gopal K, et al. Impaired branched chain amino acid oxidation contributes to cardiac insulin resistance in heart failure. Cardiovasc Diabetol. (2019) 18:86. doi: 10.1186/s12933-019-0892-3

36. Sun H, Olson KC, Gao C, Prosdocimo DA, Zhou M, Wang Z, et al. Catabolic defect of branched-chain amino acids promotes heart failure. Circulation. (2016) 133:2038-49. doi: 10.1161/CIRCULATIONAHA.115.020226

37. Chen M, Gao C, Yu J, Ren S, Wang M, Wynn RM, et al. Therapeutic effect of targeting branched-chain amino acid catabolic flux in pressure-overload induced heart failure. J Am Heart Asso. (2019) 8:e011625. doi: 10.1161/JAHA.118.011625

38. Aksentijević D, Karlstaedt A, Basalay MV, O’Brien BA, Sanchez-Tatay D, Eminaga $S$, et al. Intracellular sodium elevation reprograms cardiac metabolism. Nat Commun. (2020) 11:4337. doi: 10.1038/s41467-020-18160-x

39. Mullens W, Verbrugge FH, Nijst P, Tang WHW. Renal sodium avidity in heart failure: from pathophysiology to treatment strategies. Eur Heart J. (2017) 38:1872-82. doi: 10.1093/eurheartj/ehx035

40. Baartscheer A, Schumacher CA, van Borren MM, Belterman CN, Coronel $\mathrm{R}$, Fiolet JW. Increased $\mathrm{Na}+/ \mathrm{H}+$-exchange activity is the cause of increased $[\mathrm{Na}+] \mathrm{i}$ and underlies disturbed calcium handling in the rabbit pressure and volume overload heart failure model. Cardiovasc Res. (2003) 57:101524. doi: 10.1016/S0008-6363(02)00809-X

41. Eisner DA, Caldwell JL, Trafford AW, Hutchings DC. The control of diastolic calcium in the heart: basic mechanisms and functional implications. Circ Res. (2020) 126:395-412. doi: 10.1161/CIRCRESAHA.119.315891

42. Boyman L, Karbowski M, Lederer WJ. Regulation of mitochondrial ATP production: $\mathrm{Ca}(2+)$ signaling and quality control. Trends Mol Med. (2020) 26:21-39. doi: 10.1016/j.molmed.2019.10.007
43. Dridi H, Kushnir A, Zalk R, Yuan Q, Melville Z, Marks AR. Intracellular calcium leak in heart failure and atrial fibrillation: a unifying mechanism and therapeutic target. Nat Rev Cardiol. (2020) 17:732-47. doi: 10.1038/s41569-020-0394-8

44. Ruiz-Meana M, Minguet M, Bou-Teen D, Miro-Casas E, Castans C, Castellano J, et al. Ryanodine receptor glycation favors mitochondrial damage in the senescent heart. Circulation. (2019) 139:949-64. doi: 10.1161/CIRCULATIONAHA.118.035869

45. Bertero E, Maack C. Calcium signaling and reactive oxygen species in mitochondria. Circ Res. (2018) 122:146078. doi: 10.1161/CIRCRESAHA.118.310082

46. Zhang J, Abel ED. Effective metabolic approaches for the energy starved failing heart: bioenergetic resiliency via redundancy or something else? Circ Res. (2018) 123:329-31. doi: 10.1161/CIRCRESAHA.118.313308

47. Ardehali H, Sabbah HN, Burke MA, Sarma S, Liu PP, Cleland JG, et al. Targeting myocardial substrate metabolism in heart failure: potential for new therapies. Eur J Heart Fail. (2012) 14:120-9. doi: 10.1093/eurjhf/hfr173

48. Chen $\mathrm{Z}$, Liu M, Li L, Chen L. Involvement of the Warburg effect in non-tumor diseases processes. J Cell Physiol. (2018) 233:283949. doi: $10.1002 /$ jcp. 25998

49. Briasoulis A, Androulakis E, Christophides T, Tousoulis D. The role of inflammation and cell death in the pathogenesis, progression and treatment of heart failure. Heart Fail Rev. (2016) 21:169-76. doi: 10.1007/s10741-016-9533-z

50. Chow SL, Maisel AS, Anand I, Bozkurt B, de Boer RA, Felker GM, et al. Role of biomarkers for the prevention, assessment, and management of heart failure: a scientific statement from the American heart association. Circulation. (2017) 135:e1054-91. doi: 10.1161/CIR.0000000000000490

51. Emdin M, Aimo A, Vergaro G, Bayes-Genis A, Lupón J, Latini R, et al. sST2 predicts outcome in chronic heart failure beyond NT-proBNP and high-sensitivity troponin T. J Am Coll Cardiol. (2018) 72:230920. doi: 10.1016/j.jacc.2018.08.2165

52. Martini E, Kunderfranco P, Peano C, Carullo P, Cremonesi $M$, Schorn $T$, et al. Single-cell sequencing of mouse heart immune infiltrate in pressure overload-driven heart failure reveals extent of immune activation. Circulation. (2019) 140:2089107. doi: 10.1161/CIRCULATIONAHA.119.041694

53. Abplanalp WT, Cremer S, John D, Hoffmann J, Schuhmacher B, Merten $\mathrm{M}$, et al. Clonal hematopoiesis-driver DNMT3A mutations alter immune cells in heart failure. Circ Res. (2020) 128:216-28. doi: 10.1161/CIRCRESAHA.120.317104

54. Adamo L, Rocha-Resende C, Prabhu SD, Mann DL. Reappraising the role of inflammation in heart failure. Nat Rev Cardiol. (2020) 17:26985. doi: 10.1038/s41569-019-0315-x

55. Frangogiannis NG. Regulation of the inflammatory response in cardiac repair. Circ Res. (2012) 110:159-73. doi: 10.1161/CIRCRESAHA.111.243162

56. Chen D, Assad-Kottner C, Orrego C, Torre-Amione G. Cytokines and acute heart failure. Crit Care Med. (2008) 36(Suppl. 1):S9-16. doi: 10.1097/01.CCM.0000297160.48694.90

57. Lin HB, Naito K, Oh Y, Farber G, Kanaan G, Valaperti A, et al. Innate immune Nod1/RIP2 signaling is essential for cardiac hypertrophy but requires mitochondrial antiviral signaling protein for signal transductions and energy balance. Circulation. (2020) 142:2240-58. doi: 10.1161/CIRCULATIONAHA.119.041213

58. McMaster WG, Kirabo A, Madhur MS, Harrison DG. Inflammation, immunity, and hypertensive end-organ damage. Circ Res. (2015) 116:102233. doi: 10.1161/CIRCRESAHA.116.303697

59. Sanada S, Hakuno D, Higgins LJ, Schreiter ER, McKenzie AN, Lee RT. IL-33 and ST2 comprise a critical biomechanically induced and cardioprotective signaling system. J Clin Invest. (2007) 117:1538-49. doi: 10.1172/JCI30634

60. Paulus WJ. Unfolding discoveries in heart failure. N Engl J Med. (2020) 382:679-82. doi: 10.1056/NEJMcibr1913825

61. Toldo S, Abbate A. The NLRP3 inflammasome in acute myocardial infarction. Nat Rev Cardiol. (2018) 15:20314. doi: $10.1038 /$ nrcardio. 2017.161

62. Frangogiannis NG. The extracellular matrix in ischemic and nonischemic heart failure. Circ Res. (2019) 125:11746. doi: 10.1161/CIRCRESAHA.119.311148 
63. Brakenhielm E, González A, Díez J. Role of cardiac lymphatics in myocardial edema and fibrosis: JACC review topic of the week. J Am Coll Cardiol. (2020) 76:735-44. doi: 10.1016/j.jacc.2020.05.076

64. Westermann D, Kasner M, Steendijk P, Spillmann F, Riad A, Weitmann $\mathrm{K}$, et al. Role of left ventricular stiffness in heart failure with normal ejection fraction. Circulation. (2008) 117:2051-60. doi: 10.1161/CIRCULATIONAHA.107.716886

65. Ling LH, Kistler PM, Kalman JM, Schilling RJ, Hunter RJ. Comorbidity of atrial fibrillation and heart failure. Nat Rev Cardiol. (2016) 13:13147. doi: 10.1038/nrcardio.2015.191

66. van den Berg MP, Mulder BA, Klaassen SHC, Maass AH, van Veldhuisen DJ, van der Meer P, et al. Heart failure with preserved ejection fraction, atrial fibrillation, and the role of senile amyloidosis. Eur Heart J. (2019) 40:1287-93. doi: 10.1093/eurheartj/ehz057

67. Santhanakrishnan R, Wang N, Larson MG, Magnani JW, McManus DD, Lubitz SA, et al. Atrial fibrillation begets heart failure and vice versa: temporal associations and differences in preserved versus reduced ejection fraction. Circulation. (2016) 133:484-92. doi: 10.1161/CIRCULATIONAHA.115.018614

68. Wong JA, Conen D, Van Gelder IC, McIntyre WF, Crijns HJ, Wang $\mathrm{J}$, et al. Progression of device-detected subclinical atrial fibrillation and the risk of heart failure. J Am Coll Cardiol. (2018) 71:260311. doi: 10.1016/j.jacc.2018.03.519

69. Patel RB, Vaduganathan M, Shah SJ, Butler J. Atrial fibrillation in heart failure with preserved ejection fraction: insights into mechanisms and therapeutics. Pharmacol Ther. (2017) 176:32-9. doi: 10.1016/j.pharmthera.2016.10.019

70. Yoo S, Aistrup G, Shiferaw Y, Ng J, Mohler PJ, Hund TJ, et al. Oxidative stress creates a unique, CaMKII-mediated substrate for atrial fibrillation in heart failure. JCI Insight. (2018) 3:e120728. doi: 10.1172/jci.insight.120728

71. Kutyifa V, Vermilye K, Solomon SD, McNitt S, Moss AJ, Daimee UA. Long-term outcomes of cardiac resynchronization therapy by left ventricular ejection fraction. Eur J Heart Fail. (2019) 21:360-9. doi: 10.1002/ejhf.1357

72. Wijesurendra RS, Casadei B. Mechanisms of atrial fibrillation. Heart. (2019) 105:1860-7. doi: 10.1136/heartjnl-2018-314267

73. Ballou LM, Lin RZ, Cohen IS. Control of cardiac repolarization by phosphoinositide 3-kinase signaling to ion channels. Circ Res. (2015) 116:127-37. doi: 10.1161/CIRCRESAHA.116.303975

74. Seferović PM, Petrie MC, Filippatos GS, Anker SD, Rosano G, Bauersachs J, et al. Type 2 diabetes mellitus and heart failure: a position statement from the heart failure association of the European society of cardiology. Euro J Heart Fail. (2018) 20:853-72. doi: 10.1002/ejhf.1170

75. Greene SJ, Vaduganathan M, Khan MS, Bakris GL, Weir MR, Seltzer $\mathrm{JH}$, et al. Prevalent and incident heart failure in cardiovascular outcome trials of patients with type 2 diabetes. J Am Coll Cardiol. (2018) 71:137990. doi: 10.1016/j.jacc.2018.01.047

76. Rørth R, Jhund PS, Mogensen UM, Kristensen SL, Petrie MC, Køber $\mathrm{L}$, et al. Risk of incident heart failure in patients with diabetes and asymptomatic left ventricular systolic dysfunction. Diab Care. (2018) 41:1285-91. doi: 10.2337/dc17-2583

77. Rawshani A, Rawshani A, Sattar N, Franzén S, McGuire DK, Eliasson B, et al. Relative prognostic importance and optimal levels of risk factors for mortality and cardiovascular outcomes in type 1 diabetes mellitus. Circulation. (2019) 139:190012. doi: 10.1161/CIRCULATIONAHA.118.037454

78. Dillmann WH. Diabetic cardiomyopathy. Circ Res. (2019) 124:11602. doi: 10.1161/CIRCRESAHA.118.314665

79. Taqueti VR, Di Carli MF. Coronary microvascular disease pathogenic mechanisms and therapeutic options: JACC state-of-the-art review. J Am Coll Cardiol. (2018) 72:2625-41. doi: 10.1016/j.jacc.2018.09.042

80. Riehle C, Abel ED. Insulin signaling and heart failure. Circ Res. (2016) 118:1151-69. doi: 10.1161/CIRCRESAHA.116.306206

81. Donath MY, Meier DT, Boni-Schnetzler M. Inflammation in the pathophysiology and therapy of cardiometabolic disease. Endocr Rev. (2019) 40:1080-91. doi: 10.1210/er.2019-00002

82. Fernandez-Ruiz I. A new link for heart failure and diabetes. Nat Rev Cardiol. (2019) 16:4. doi: 10.1038/s41569-018-0121-x

83. Papadaki M, Holewinski RJ, Previs SB, Martin TG, Stachowski MJ, Li A, et al. Diabetes with heart failure increases methylglyoxal modifications in the sarcomere, which inhibit function. JCI Insight. (2018) 3:e120728. doi: 10.1172/jci.insight.121264

84. Kenny HC, Abel ED. Heart failure in type 2 diabetes mellitus. Circ Res. (2019) 124:121-41. doi: 10.1161/CIRCRESAHA.118.311371

85. Packer M. Activation and inhibition of sodium-hydrogen exchanger is a mechanism that links the pathophysiology and treatment of diabetes mellitus with that of heart failure. Circulation. (2017) 136:154859. doi: 10.1161/CIRCULATIONAHA.117.030418

86. Shah MS, Brownlee M. Molecular and cellular mechanisms of cardiovascular disorders in diabetes. Circ Res. (2016) 118:180829. doi: 10.1161/CIRCRESAHA.116.306923

87. Rutten FH, Cramer MJ, Lammers JW, Grobbee DE, Hoes AW. Heart failure and chronic obstructive pulmonary disease: an ignored combination? Eur J Heart Fail. (2006) 8:706-11. doi: 10.1016/j.ejheart.2006.01.010

88. Carter P, Lagan J, Fortune C, Bhatt DL, Vestbo J, Niven R, et al. Association of cardiovascular disease with respiratory disease. J Am Coll Cardiol. (2019) 73:2166-77. doi: 10.1016/j.jacc.2018.11.063

89. Ramalho SHR, Shah AM. Lung function and cardiovascular disease: a link. Trends Cardiov Med. (2021) 31:93-8. doi: 10.1016/j.tcm.2019.12.009

90. Canepa M, Straburzynska-Migaj E, Drozdz J, Fernandez-Vivancos C, Pinilla JMG, Nyolczas N, et al. Characteristics, treatments and 1-year prognosis of hospitalized and ambulatory heart failure patients with chronic obstructive pulmonary disease in the European society of cardiology heart failure longterm registry. Eur J Heart Fail. (2018) 20:100-10. doi: 10.1002/ejhf.964

91. Morgan AD, Rothnie KJ, Bhaskaran K, Smeeth L, Quint JK. Chronic obstructive pulmonary disease and the risk of 12 cardiovascular diseases: a population-based study using UK primary care data. Thorax. (2018) 73:877-9. doi: 10.1136/thoraxjnl-2017-210865

92. Roversi S, Fabbri LM, Sin DD, Hawkins NM, Agustí A. Chronic obstructive pulmonary disease and cardiac diseases. An urgent need for integrated care. Am J Respir Crit Care Med. (2016) 194:131936. doi: 10.1164/rccm.201604-0690SO

93. Singh D, Agusti A, Anzueto A, Barnes PJ, Bourbeau J, Celli BR, et al. Global strategy for the diagnosis, management, and prevention of chronic obstructive lung disease: the GOLD science committee report 2019. Eur Respir J. (2019) 53:1900164. doi: 10.1183/13993003.00164-2019

94. Stone IS, Barnes NC, James WY, Midwinter D, Boubertakh R, Follows $\mathrm{R}$, et al. Lung deflation and cardiovascular structure and function in chronic obstructive pulmonary disease. A randomized controlled trial. Am J Respir Crit Care Med. (2016) 193:717-26. doi: 10.1164/rccm.201508$1647 \mathrm{OC}$

95. Hawkins NM, Virani S, Ceconi C. Heart failure and chronic obstructive pulmonary disease: the challenges facing physicians and health services. Eur Heart J. (2013) 34:2795-803. doi: 10.1093/eurheartj/eht192

96. Rocha A, Arbex FF, Sperandio PA, Souza A, Biazzim L, Mancuso F, et al. Excess ventilation in chronic obstructive pulmonary disease-heart failure overlap. Implications for dyspnea and exercise intolerance. Am J Respir Crit Care Med. (2017) 196:1264-74. doi: 10.1164/rccm.2017040675OC

97. Horwich TB, Broderick S, Chen L, McCullough PA, Strzelczyk T, Kitzman DW, et al. Relation among body mass index, exercise training, and outcomes in chronic systolic heart failure. Am J Cardiol. (2011) 108:17549. doi: 10.1016/j.amjcard.2011.07.051

98. Kapoor JR, Heidenreich PA. Obesity and survival in patients with heart failure and preserved systolic function: a U-shaped relationship. Am Heart J. (2010) 159:75-80. doi: 10.1016/j.ahj.2009.10.026

99. Pandey A, LaMonte M, Klein L, Ayers C, Psaty BM, Eaton CB, et al. Relationship between physical activity, body mass index, and risk of heart failure. J Am Coll Cardiol. (2017) 69:1129-42. doi: 10.1016/j.jacc.2016.11.081

100. Streng KW, Voors AA, Hillege HL, Anker SD, Cleland JG, Dickstein K, et al. Waist-to-hip ratio and mortality in heart failure. Euro J Heart Fail. (2018) 20:1269-77. doi: 10.1002/ejhf.1244

101. Tsujimoto T, Kajio H. Abdominal obesity is associated with an increased risk of all-cause mortality in patients with HFpEF. J Am Coll Cardiol. (2017) 70:2739-49. doi: 10.1016/j.jacc.2017.09.1111

102. Packer M. Obesity-associated heart failure as a theoretical target for treatment with mineralocorticoid receptor antagonists. JAMA Cardiol. (2018) 3:883-7. doi: 10.1001/jamacardio.2018.2090 
103. Lavie CJ, Ozemek C, Carbone S, Katzmarzyk PT, Blair SN. Sedentary behavior, exercise, and cardiovascular health. Circ Res. (2019) 124:799815. doi: 10.1161/CIRCRESAHA.118.312669

104. Mouton AJ, Li X, Hall ME, Hall JE. Obesity, hypertension, and cardiac dysfunction: novel roles of immunometabolism in macrophage activation and inflammation. Circ Res. (2020) 126:789-806. doi: 10.1161/CIRCRESAHA.119.312321

105. Sweeney G. Cardiovascular effects of leptin. Nat Rev Cardiol. (2010) 7:229. doi: 10.1038/nrcardio.2009.224

106. Packer M. Leptin-aldosterone-neprilysin axis: identification of its distinctive role in the pathogenesis of the three phenotypes of heart failure in people with obesity. Circulation. (2018) 137:1614-31. doi: 10.1161/CIRCULATIONAHA.117.032474

107. Mechanick JI, Farkouh ME, Newman JD, Garvey WT. Cardiometabolic-based chronic disease, adiposity and dysglycemia drivers: JACC state-of-the-art review. J Am Coll Cardiol. (2020) 75:525-38. doi: 10.1016/j.jacc.2019.11.044

108. Abel ED, Litwin SE, Sweeney G. Cardiac remodeling in obesity. Physiol Rev. (2008) 88:389-419. doi: 10.1152/physrev.00017.2007

109. Suthahar N, Meijers WC, Ho JE, Gansevoort RT, Voors AA, van der Meer $\mathrm{P}$, et al. Sex-specific associations of obesity and N-terminal pro-B-type natriuretic peptide levels in the general population. Eur J Heart Fail. (2018) 20:1205-14. doi: 10.1002/ejhf.1209

110. Nadruz Jr W, Claggett BL, McMurray JJ, Packer M, Zile MR, et al. Impact of body mass index on the accuracy of n-terminal probrain natriuretic peptide and brain natriuretic peptide for predicting outcomes in patients with chronic heart failure and reduced ejection fraction: insights from the PARADIGM-HF study (prospective comparison of ARNI with ACEI to determine impact on global mortality and morbidity in heart failure trial). Circulation. (2016) 134:1785-7. doi: 10.1161/CIRCULATIONAHA.116.024976

111. Kälsch H, Neumann T, Erbel R. Less increase of BNP and NT-proBNP levels in obese patient with decompensated heart failure: interpretation of natriuretic peptides in obesity. Int J Cardiol. (2009) 133:e224. doi: 10.1016/j.ijcard.2007.08.098

112. Díez J. Chronic heart failure as a state of reduced effectiveness of the natriuretic peptide system: implications for therapy. Eur J Heart Fail. (2017) 19:167-76. doi: 10.1002/ejhf.656

113. de Boer RA, Hulot JS, Tocchetti CG, Aboumsallem JP, Ameri P, Anker SD, et al. Common mechanistic pathways in cancer and heart failure. A scientific roadmap on behalf of the translational research committee of the heart failure association (HFA) of the European society of cardiology (ESC). Eur J Heart Fail. (2020) 22:2272-89. doi: 10.1002/ejhf.2029

114. de Boer RA, Meijers WC, van der Meer P, van Veldhuisen DJ. Cancer and heart disease: associations and relations. Eur J Heart Fail. (2019) 21:151525. doi: 10.1002/ejhf.1539

115. Anker MS, Sanz AP, Zamorano JL, Mehra MR, Butler J, Riess H, et al. Advanced cancer is also a heart failure syndrome - an hypothesis. Eur J Heart Fail. (2020) 23:140-4. doi: 10.1002/jcsm.12694

116. Libby P, Sidlow R, Lin AE, Gupta D, Jones LW, Moslehi J, et al. Clonal hematopoiesis: crossroads of aging, cardiovascular disease, and cancer: JACC review topic of the week. J Am Coll Cardiol. (2019) 74:56777. doi: 10.1016/j.jacc.2019.06.007

117. Varga ZV, Ferdinandy P, Liaudet L, Pacher P. Drug-induced mitochondrial dysfunction and cardiotoxicity. Am J Physiol Heart Circul Physiol. (2015) 309:H1453-67. doi: 10.1152/ajpheart.00554.2015

118. Liu Y, Asnani A, Zou L, Bentley VL, Yu M, Wang Y, et al. Visnagin protects against doxorubicin-induced cardiomyopathy through modulation of mitochondrial malate dehydrogenase. Sci Trans Med. (2014) 6:266ra170. doi: 10.1126/scitranslmed.3010189

119. Pudil R, Mueller C, Celutkiene J, Henriksen PA, Lenihan D, Dent S, et al. Role of serum biomarkers in cancer patients receiving cardiotoxic cancer therapies: a position statement from the cardio-oncology study group of the heart failure association and the cardio-oncology council of the european society of cardiology. Euro J Heart Fail. (2020) 22:196683. doi: 10.1002/ejhf.2017

120. Khosrow-Khavar F, Filion KB, Bouganim N, Suissa S, Azoulay L. Aromatase inhibitors and the risk of cardiovascular outcomes in women with breast cancer: a population-based cohort study. Circulation. (2020) 141:54959. doi: 10.1161/CIRCULATIONAHA.119.044750

121. Boekel NB, Duane FK, Jacobse JN, Hauptmann M, Schaapveld M, Sonke GS, et al. Heart failure after treatment for breast cancer. Eur J Heart Fail. (2020) 22:366-74. doi: 10.1002/ejhf.1620

122. Banke A, Fosbøl EL, Møller JE, Gislason GH, Andersen M, Bernsdorf M, et al. Long-term effect of epirubicin on incidence of heart failure in women with breast cancer: insight from a randomized clinical trial. Eur J Heart Fail. (2018) 20:1447-53. doi: 10.1002/ejhf.1168

123. Salz T, Zabor EC, de Nully Brown P, Dalton SO, Raghunathan NJ, Matasar $\mathrm{MJ}$, et al. Preexisting cardiovascular risk and subsequent heart failure among non-hodgkin lymphoma survivors. J Clin Oncol. (2017) 35:383743. doi: 10.1200/JCO.2017.72.4211

124. Goldhar HA, Yan AT, Ko DT, Earle CC, Tomlinson GA, Trudeau ME, et al. The temporal risk of heart failure associated with adjuvant trastuzumab in breast cancer patients: a population study. J Nation Cancer Inst. (2016) 108:djv301. doi: 10.1093/jnci/djv301

125. Zhang S, Liu X, Bawa-Khalfe T, Lu LS, Lyu YL, Liu LF, et al. Identification of the molecular basis of doxorubicin-induced cardiotoxicity. Nat Med. (2012) 18:1639-42. doi: 10.1038/nm.2919

126. Roger VL, Go AS, Lloyd-Jones DM, Adams RJ, Berry JD, Brown TM, et al. Heart disease and stroke statistics-2011 update: a report from the American heart association. Circulation. (2011) 123:e18209. doi: 10.1161/CIR.0b013e3182009701

127. Lara KM, Levitan EB, Gutierrez OM, Shikany JM, Safford MM, Judd SE, et al. Dietary patterns and incident heart failure in U.S. Adults without known coronary disease. J Am Coll Cardiol. (2019) 73:203645. doi: 10.1016/j.jacc.2019.01.067

128. Larsson SC, Orsini N, Wolk A. Alcohol consumption and risk of heart failure: a dose-response meta-analysis of prospective studies. Eur J Heart Fail. (2015) 17:367-73. doi: 10.1002/ejhf.228

129. Schloss MJ, Swirski FK, Nahrendorf M. Modifiable cardiovascular risk, hematopoiesis, and innate immunity. Circ Res. (2020) 126:1242-59. doi: 10.1161/CIRCRESAHA.120.315936

130. Chudasama YV, Khunti K, Gillies CL, Dhalwani NN, Davies MJ, Yates T, et al. Healthy lifestyle and life expectancy in people with multimorbidity in the UK biobank: a longitudinal cohort study. PLoS Med. (2020) 17:e1003332. doi: 10.1371/journal.pmed.1003332

131. Barnes PJ. Mechanisms of development of multimorbidity in the elderly. Eur Respir J. (2015) 45:790-806. doi: 10.1183/09031936.00229714

132. Forman DE, Maurer MS, Boyd C, Brindis R, Salive ME, Horne FM, et al. Multimorbidity in older adults with cardiovascular disease. J Am Coll Cardiol. (2018) 71:2149-61. doi: 10.1016/j.jacc.2018.03.022

133. Sharma K, Kass DA. Heart failure with preserved ejection fraction. Cir Res. (2014) 115:79-96. doi: 10.1161/CIRCRESAHA.115.302922

134. Ajoolabady A, Aslkhodapasandhokmabad H, Aghanejad A, Zhang Y, Ren J. Mitophagy receptors and mediators: therapeutic targets in the management of cardiovascular ageing. Ageing Res Rev. (2020) 62:101129. doi: 10.1016/j.arr.2020.101129

135. Lesnefsky EJ, Chen Q, Hoppel CL. Mitochondrial metabolism in aging heart. Circ Res. (2016) 118:1593-611. doi: 10.1161/CIRCRESAHA.116.307505

136. Ferrucci L, Fabbri E. Inflammageing: chronic inflammation in ageing, cardiovascular disease, and frailty. Nat Rev Cardiol. (2018) 15:50522. doi: 10.1038/s41569-018-0064-2

137. Miyamoto S. Autophagy and cardiac aging. Cell Death Diff. (2019) 26:65364. doi: 10.1038/s41418-019-0286-9

138. Sack MN, Fyhrquist FY, Saijonmaa OJ, Fuster V, Kovacic JC. Basic biology of oxidative stress and the cardiovascular system: part 1 of a 3-part series. J Am Coll Cardiol. (2017) 70:196-211. doi: 10.1016/j.jacc.2017.05.034

139. Ng R, Sutradhar R, Yao Z, Wodchis WP, Rosella LC. Smoking, drinking, diet and physical activity-modifiable lifestyle risk factors and their associations with age to first chronic disease. Int J Epidemiol. (2020) 49:11330. doi: 10.1093/ije/dyz078

140. Harrington JL, Ayers C, Berry JD, Omland T, Pandey A, Seliger SL, et al. Sedentary behavior and subclinical cardiac injury: results from the dallas heart study. Circulation. (2017) 136:1451-3. doi: 10.1161/CIRCULATIONAHA.117. 
141. Bricca A, Harris LK, Jäger M, Smith SM, Juhl CB, Skou ST. Benefits and harms of exercise therapy in people with multimorbidity: a systematic review and meta-analysis of randomised controlled trials. Ageing Res Rev. (2020) 63:101166. doi: 10.1016/j.arr.2020.101166

142. Gan Z, Fu T, Kelly DP, Vega RB. Skeletal muscle mitochondrial remodeling in exercise and diseases. Cell Res. (2018) 28:96980. doi: 10.1038/s41422-018-0078-7

143. Vega RB, Konhilas JP, Kelly DP, Leinwand LA. Molecular mechanisms underlying cardiac adaptation to exercise. Cell Metabo. (2017) 25:101226. doi: 10.1016/j.cmet.2017.04.025

144. Karstoft K, Pedersen BK. Exercise and type 2 diabetes: focus on metabolism and inflammation. Immunol Cell Biol. (2016) 94:146-50. doi: 10.1038/icb.2015.101

145. Zhou Y, Zhou B, Pache L, Chang M, Khodabakhshi AH, Tanaseichuk $\mathrm{O}$, et al. Metascape provides a biologist-oriented resource for the analysis of systems-level datasets. Nat Commun. (2019) 10:1523. doi: 10.1038/s41467-019-09234-6

146. Han H, Cho JW, Lee S, Yun A, Kim H, Bae D, et al. TRRUST v2: an expanded reference database of human and mouse transcriptional regulatory interactions. Nucleic Acids Res. (2018) 46(D1):D380-d6. doi: 10.1093/nar/gkx1013

147. Zhang Y, Murugesan P, Huang K, Cai H. NADPH oxidases and oxidase crosstalk in cardiovascular diseases: novel therapeutic targets. Nat Rev Cardiol. (2020) 17:170-94. doi: 10.1038/s41569-019-0260-8

148. Hoes MF, Grote Beverborg N, Kijlstra JD, Kuipers J, Swinkels DW, Giepmans $\mathrm{BNG}$, et al. Iron deficiency impairs contractility of human cardiomyocytes through decreased mitochondrial function. Eur J Heart Fail. (2018) 20:9109. doi: 10.1002/ejhf.1154

149. Maillet M, van Berlo JH, Molkentin JD. Molecular basis of physiological heart growth: fundamental concepts and new players. Nat Rev Mol Cell Biol. (2013) 14:38-48. doi: 10.1038/nrm3495

150. Zhao Z, Li R, Wang X, Li J, Yuan M, Liu E, et al. Attenuation of atrial remodeling by aliskiren via affecting oxidative stress, inflammation and PI3K/Akt signaling pathway. Cardiovasc Drugs Ther. (2020). doi: 10.1007/s10557-020-07002-z. [Epub ahead of print].

151. Barnes PJ, Baker J, Donnelly LE. Cellular senescence as a mechanism and target in chronic lung diseases. Am J Respir Crit Care Med. (2019) 200:55664. doi: 10.1164/rccm.201810-1975TR

152. An R, Zhao L, Xi C, Li H, Shen G, Liu H, et al. Melatonin attenuates sepsisinduced cardiac dysfunction via a PI3K/Akt-dependent mechanism. Basic Res Cardiol. (2016) 111:8. doi: 10.1007/s00395-015-0526-1

153. Belaidi E, Morand J, Gras E, Pépin JL, Godin-Ribuot D. Targeting the ROS-HIF-1-endothelin axis as a therapeutic approach for the treatment of obstructive sleep apnea-related cardiovascular complications. Pharmacol Ther. (2016) 168:1-11. doi: 10.1016/j.pharmthera.2016. 07.010

154. Khan MI, Rath S, Adhami VM, Mukhtar H. Hypoxia driven glycation: mechanisms and therapeutic opportunities. Sem Cancer Biol. (2018) 49:7582. doi: 10.1016/j.semcancer.2017.05.008

155. Sundaresan NR, Vasudevan P, Zhong L, Kim G, Samant S, Parekh V, et al. The sirtuin SIRT6 blocks IGF-Akt signaling and development of cardiac hypertrophy by targeting c-Jun. Nat Med. (2012) 18:164350. doi: $10.1038 / \mathrm{nm} .2961$

156. Wo D, Peng J, Ren DN, Qiu L, Chen J, Zhu Y, et al. Opposing roles of wnt inhibitors IGFBP-4 and Dkk1 in cardiac ischemia by differential targeting of LRP5/6 and $\beta$-catenin. Circulation. (2016) 134:19912007. doi: 10.1161/CIRCULATIONAHA.116.024441

157. Luczak ED, Wu Y, Granger JM, Joiner MA, Wilson NR, Gupta A, et al. Mitochondrial CaMKII causes adverse metabolic reprogramming and dilated cardiomyopathy. Nat Commun. (2020) 11:4416. doi: 10.1038/s41467-020-18165-6

158. Pfleger J, Gresham K, Koch WJ. G protein-coupled receptor kinases as therapeutic targets in the heart. Nat Rev Cardiol. (2019) 16:61222. doi: 10.1038/s41569-019-0220-3

159. Sidlow R, Lin AE, Gupta D, Bolton KL, Steensma DP, Levine RL, et al. The clinical challenge of clonal hematopoiesis, a newly recognized cardiovascular risk factor. JAMA Cardiol. (2020). doi: 10.1001/jamacardio.2020.1271. [Epub ahead of print].
160. Meng L, Li XY, Shen L, Ji HF. Type 2 diabetes mellitus drugs for alzheimer's disease: current evidence and therapeutic opportunities. Trends Mol Med. (2020) 26:597-614. doi: 10.1016/j.molmed.2020.02.002

161. Koitabashi N, Kass DA. Reverse remodeling in heart failuremechanisms and therapeutic opportunities. Nat Rev Cardiol. (2011) 9:147-57. doi: 10.1038/nrcardio.2011.172

162. Tousoulis D, Oikonomou E, Siasos G, Stefanadis C. Statins in heart failureWith preserved and reduced ejection fraction. An update. Pharmacol Ther. (2014) 141:79-91. doi: 10.1016/j.pharmthera.2013.09.001

163. Nakamura M, Sadoshima J. Mechanisms of physiological and pathological cardiac hypertrophy. Nat Rev Cardiol. (2018) 15:387-407. doi: 10.1038/s41569-018-0007-y

164. Venot Q, Blanc T, Rabia SH, Berteloot L, Ladraa S, Duong JP, et al. Targeted therapy in patients with PIK3CA-related overgrowth syndrome. Nature. (2018) 558:540-6. doi: 10.1038/s41586-018-0217-9

165. Faria A, Persaud SJ. Cardiac oxidative stress in diabetes: mechanisms and therapeutic potential. Pharmacol Ther. (2017) 172:50-62. doi: 10.1016/j.pharmthera.2016.11.013

166. Chan JY, Chan SH. Activation of endogenous antioxidants as a common therapeutic strategy against cancer, neurodegeneration and cardiovascular diseases: a lesson learnt from DJ-1. Pharmacol Ther. (2015) 156:6974. doi: 10.1016/j.pharmthera.2015.09.005

167. Brown DA, Perry JB, Allen ME, Sabbah HN, Stauffer BL, Shaikh SR, et al. Expert consensus document: mitochondrial function as a therapeutic target in heart failure. Nat Rev Cardiol. (2017) 14:23850. doi: 10.1038/nrcardio.2016.203

168. Lam CSP, Voors AA, de Boer RA, Solomon SD, van Veldhuisen DJ. Heart failure with preserved ejection fraction: from mechanisms to therapies. Eur Heart J. (2018) 39:2780-92. doi: 10.1093/eurheartj/ehy301

169. Rocha M, Apostolova N, Diaz-Rua R, Muntane J, Victor VM. Mitochondria and T2D: role of autophagy, ER stress, and inflammasome. Trends Endocrinol Metab. (2020) 31:725-41. doi: 10.1016/j.tem.2020.03.004

170. Koliaki C, Roden M. Alterations of mitochondrial function and insulin sensitivity in human obesity and diabetes mellitus. Ann Rev Nutr. (2016) 36:337-67. doi: 10.1146/annurev-nutr-071715-050656

171. Rowlands DJ. Mitochondria dysfunction: a novel therapeutic target in pathological lung remodeling or bystander? Pharmacol Ther. (2016) 166:96105. doi: 10.1016/j.pharmthera.2016.06.019

172. Piantadosi CA, Suliman HB. Mitochondrial dysfunction in lung pathogenesis. Ann Rev Physiol. (2017) 79:495515. doi: 10.1146/annurev-physiol-022516-034322

173. Morava E, Kozicz T. Mitochondria and the economy of stress (mal)adaptation. Neuro Bio Rev. (2013) 37:66880. doi: 10.1016/j.neubiorev.2013.02.005

174. van der Meer P, van der Wal HH, Melenovsky V. Mitochondrial function, skeletal muscle metabolism, and iron deficiency in heart failure. Circulation. (2019) 139:2399-402. doi: 10.1161/CIRCULATIONAHA.119.040134

175. Khan RS, Bril F, Cusi K, Newsome PN. Modulation of insulin resistance in nonalcoholic fatty liver disease. Hepatol. (2019) 70:711-24. doi: 10.1002/hep.30429

176. Mesarwi OA, Loomba R, Malhotra A. Obstructive sleep apnea, hypoxia, and nonalcoholic fatty liver disease. Am J Respir Crit Care Med. (2019) 199:830-41. doi: 10.1164/rccm.201806-1109TR

177. Forbes JM, Thorburn DR. Mitochondrial dysfunction in diabetic kidney disease. Nat Rev Nephrol. (2018) 14:291-312. doi: 10.1038/nrneph.2018.9

178. Packer M. Autophagy-dependent and -independent modulation of oxidative and organellar stress in the diabetic heart by glucose-lowering drugs. Cardiovasc Diabetol. (2020) 19:62. doi: 10.1186/s12933-020-01041-4

179. Javadov S, Jang S, Agostini B. Crosstalk between mitogen-activated protein kinases and mitochondria in cardiac diseases: therapeutic perspectives. Pharmacol Ther. (2014) 144:202-25. doi: 10.1016/j.pharmthera.2014.05.013

180. Delbridge LMD, Mellor KM, Taylor DJ, Gottlieb RA. Myocardial stress and autophagy: mechanisms and potential therapies. Nat Rev Cardiol. (2017) 14:412-25. doi: 10.1038/nrcardio.2017.35

181. Neeland IJ, Poirier P, Després JP. Cardiovascular and metabolic heterogeneity of obesity: clinical challenges and implications for management. Circulation. (2018) 137:1391406. doi: 10.1161/CIRCULATIONAHA.117.029617 
182. Hall JA, Ramachandran D, Roh HC, DiSpirito JR, Belchior T, Zushin $\mathrm{PH}$, et al. Obesity-linked PPAR $\gamma$ S273 phosphorylation promotes insulin resistance through growth differentiation factor 3. Cell Metab. (2020) 32:665-75.e6. doi: 10.1016/j.cmet.2020.08.016

183. Cosmi F, Shen L, Magnoli M, Abraham WT, Anand IS, Cleland JG, et al. Treatment with insulin is associated with worse outcome in patients with chronic heart failure and diabetes. Eur J Heart Fail. (2018) 20:88895. doi: 10.1002/ejhf.1146

184. Kaplanski G. Interleukin-18: biological properties and role in disease pathogenesis. Immunol Rev. (2018) 281:138-53. doi: 10.1111/imr.12616

185. Pinar AA, Scott TE, Huuskes BM, Tapia Cáceres FE, KempHarper BK, Samuel CS. Targeting the NLRP3 inflammasome to treat cardiovascular fibrosis. Pharmacol Ther. (2020) 209:107511. doi: 10.1016/j.pharmthera.2020.107511

186. Birrell MA, Eltom S. The role of the NLRP3 inflammasome in the pathogenesis of airway disease. Pharmacol Ther. (2011) 130:36470. doi: $10.1016 /$ j.pharmthera.2011.03.007

187. Wada J, Makino H. Innate immunity in diabetes and diabetic nephropathy. Nat Rev Nephrol. (2016) 12:13-26. doi: 10.1038/nrneph.2015.175

188. Komada T, Muruve DA. The role of inflammasomes in kidney disease. Nat Rev Nephrol. (2019) 15:501-20. doi: 10.1038/s41581-019-0158-Z

189. Livshits G, Kalinkovich A. Inflammaging as a common ground for the development and maintenance of sarcopenia, obesity, cardiomyopathy and dysbiosis. Ageing Res Rev. (2019) 56:100980. doi: 10.1016/j.arr.2019.100980

190. McElvaney OJ, McEvoy NL, McElvaney OF, Carroll TP, Murphy MP, Dunlea DM, et al. Characterization of the inflammatory response to severe COVID-19 illness. Am J Respir Crit Care Med. (2020) 202:81221. doi: 10.1164/rccm.202005-1583OC

191. Sanders-van Wijk S, Tromp J, Beussink-Nelson L, Hage C, Svedlund $\mathrm{S}$, Saraste A, et al. Proteomic evaluation of the comorbidityinflammation paradigm in heart failure with preserved ejection fraction: results from the PROMIS-HFpEF study. Circulation. (2020) 142:2029-44. doi: 10.1161/CIRCULATIONAHA.120.045810

192. Deng Y, Xie M, Li Q, Xu X, Ou W, Zhang Y, et al. Targeting mitochondriainflammation circuit by $\beta$-Hydroxybutyrate mitigates HFpEF. Circ Res. (2020) 128:232-45. doi: 10.1161/CIRCRESAHA.120.317933

193. Suetomi T, Willeford A, Brand CS, Cho Y, Ross RS, Miyamoto $\mathrm{S}$, et al. Inflammation and NLRP3 inflammasome activation initiated in response to pressure overload by $\mathrm{Ca}(2+) /$ calmodulindependent protein kinase II $\delta$ signaling in cardiomyocytes are essential for adverse cardiac remodeling. Circulation. (2018) 138:2530-44. doi: 10.1161/CIRCULATIONAHA.118.034621

194. Balic JJ, Albargy H, Luu K, Kirby FJ, Jayasekara WSN, Mansell $\mathrm{F}$, et al. STAT3 serine phosphorylation is required for TLR4 metabolic reprogramming and IL-1 $\beta$ expression. Nat Commun. (2020) 11:3816. doi: 10.1038/s41467-020-17669-5

195. Nan J, Hu H, Sun Y, Zhu L, Wang Y, Zhong Z, et al. TNFR2 stimulation promotes mitochondrial fusion via Stat3- and NF-kBdependent activation of OPA1 expression. Circ Res. (2017) 121:392410. doi: 10.1161/CIRCRESAHA.117.311143

196. Palomer X, Román-Azcona MS, Pizarro-Delgado J, Planavila A, Villarroya F, Valenzuela-Alcaraz B, et al. SIRT3-mediated inhibition of FOS through histone $\mathrm{H} 3$ deacetylation prevents cardiac fibrosis and inflammation. Signal Trans Target Ther. (2020) 5:14. doi: 10.1038/s41392-020-0114-1

197. Bilchick K, Kothari H, Narayan A, Garmey J, Omar A, Capaldo B, et al. Cardiac resynchronization therapy reduces expression of inflammationpromoting genes related to interleukin- $1 \beta$ in heart failure. Cardiovasc Res. (2020) 116:1311-22. doi: 10.1093/cvr/cvz232

198. Chen J, Chen S, Zhang B, Liu J. SIRT3 as a potential therapeutic target for heart failure. Pharmacol Res. (2021) 165:105432. doi: 10.1016/j.phrs.2021.105432

199. Warren JS, Oka SI, Zablocki D, Sadoshima J. Metabolic reprogramming via PPAR $\alpha$ signaling in cardiac hypertrophy and failure: From metabolomics to epigenetics. Am J Physiol Heart Cir Physiol. (2017) 313:H58496. doi: 10.1152/ajpheart.00103.2017

200. Zang H, Mathew RO, Cui T. The dark side of Nrf2 in the heart. Front Physiol. (2020) 11:722. doi: 10.3389/fphys.2020.00722
201. Pushpakom S, Iorio F, Eyers PA, Escott KJ, Hopper S, Wells A, et al. Drug repurposing: progress, challenges and recommendations. Nat Rev Drug Discov. (2019) 18:41-58. doi: 10.1038/nrd.2018.168

202. Shannon P, Markiel A, Ozier O, Baliga NS, Wang JT, Ramage $D$, et al. Cytoscape: a software environment for integrated models of biomolecular interaction networks. Genome Res. (2003) 13:2498-504. doi: 10.1101/gr.1239303

203. Everett BM, Cornel JH, Lainscak M, Anker SD, Abbate A, Thuren $\mathrm{T}$, et al. Anti-inflammatory therapy with canakinumab for the prevention of hospitalization for heart failure. Circulation. (2019) 139:1289-99. doi: 10.1161/CIRCULATIONAHA.118. 038010

204. Ridker PM, MacFadyen JG, Glynn RJ, Koenig W, Libby P, Everett BM, et al. Inhibition of interleukin- $1 \beta$ by canakinumab and cardiovascular outcomes in patients with chronic kidney disease. J Am Coll Cardiol. (2018) 71:240514. doi: 10.1016/j.jacc.2018.03.490

205. Everett BM, Donath MY, Pradhan AD, Thuren T, Pais P, Nicolau JC, et al. Anti-inflammatory therapy with canakinumab for the prevention and management of diabetes. J Am Coll Cardiol. (2018) 71:2392401. doi: 10.1016/j.jacc.2018.03.002

206. Abbate A, Toldo S, Marchetti C, Kron J, Van Tassell BW, Dinarello CA. Interleukin-1 and the inflammasome as therapeutic targets in cardiovascular disease. Circ Res. (2020) 126:126080. doi: 10.1161/CIRCRESAHA.120.315937

207. Hippisley-Cox J, Coupland C. Diabetes treatments and risk of heart failure, cardiovascular disease, and all cause mortality: cohort study in primary care. BMJ. (2016) 354:i3477. doi: 10.1136/bmj.i3477

208. Januzzi J, Ferreira JP, Böhm M, Kaul S, Wanner C, Brueckmann M, et al. Empagliflozin reduces the risk of a broad spectrum of heart failure outcomes regardless of heart failure status at baseline. Eur J Heart Fail. (2019) 21:3868. doi: 10.1002/ejhf.1419

209. Fitchett D, Butler J, van de Borne P, Zinman B, Lachin JM, Wanner C, et al. Effects of empagliflozin on risk for cardiovascular death and heart failure hospitalization across the spectrum of heart failure risk in the EMPA-REG OUTCOME®) trial. Eur Heart J. (2018) 39:36370. doi: 10.1093/eurheartj/ehx511

210. Zinman B, Wanner C, Lachin JM, Fitchett D, Bluhmki E, Hantel S, et al. Empagliflozin, cardiovascular outcomes, and mortality in type 2 diabetes. $N$ Engl J Med. (2015) 373:2117-28. doi: 10.1056/NEJMoa1504720

211. Mudaliar S, Alloju S, Henry RR. Can a shift in fuel energetics explain the beneficial cardiorenal outcomes in the EMPA-REG OUTCOME study? A unifying hypothesis. Diabetes care. (2016) 39:1115-22. doi: 10.2337/dc16-0542

212. McGuire DK, Alexander JH, Johansen OE, Perkovic V, Rosenstock $\mathrm{J}$, Cooper ME, et al. Linagliptin effects on heart failure and related outcomes in individuals with type 2 diabetes mellitus at high cardiovascular and renal risk in CARMELINA. Circulation. (2019) 139:351-61. doi: 10.1161/CIRCULATIONAHA.118.038352

213. Scheen AJ. Cardiovascular effects of new oral glucose-lowering agents: DPP-4 and SGLT-2 inhibitors. Circ Res. (2018) 122:143959. doi: 10.1161/CIRCRESAHA.117.311588

214. Bridges HR, Jones AJ, Pollak MN, Hirst J. Effects of metformin and other biguanides on oxidative phosphorylation in mitochondria. Bio J. (2014) 462:475-87. doi: 10.1042/BJ20140620

215. Kim TT, Dyck JR. Is AMPK the savior of the failing heart? Trends Endocrinol Metab. (2015) 26:40-8. doi: 10.1016/j.tem.2014.11.001

216. Das A, Durrant D, Salloum FN, Xi L, Kukreja RC. PDE5 inhibitors as therapeutics for heart disease, diabetes and cancer. Pharmacol Ther. (2015) 147:12-21. doi: 10.1016/j.pharmthera.2014.10.003

217. Luongo TS, Eller JM, Lu MJ, Niere M, Raith F, Perry C, et al. SLC25A51 is a mammalian mitochondrial $\mathrm{NAD}(+)$ transporter. Nature. (2020) 588:174-9. doi: 10.1038/s41586-020-2741-7

218. Chioncel O, Lainscak M, Seferovic PM, Anker SD, Crespo-Leiro MG, Harjola VP, et al. Epidemiology and one-year outcomes in patients with chronic heart failure and preserved, mid-range and reduced ejection fraction: an analysis of the ESC heart failure long-term registry. Eur J Heart Fail. (2017) 19:1574-85. doi: 10.1002/ejhf.813 
219. Dunlay SM, Roger VL, Redfield MM. Epidemiology of heart failure with preserved ejection fraction. Nat Rev Cardiol. (2017) 14:591602. doi: 10.1038/nrcardio.2017.65

220. Shah KS, Xu H, Matsouaka RA, Bhatt DL, Heidenreich PA, Hernandez $\mathrm{AF}$, et al. Heart failure with preserved, borderline, and reduced ejection fraction: 5-year outcomes. J Am Coll Cardiol. (2017) 70:2476-86. doi: 10.1016/j.jacc.2017.08.074

221. Mehmood M. Obstructive sleep apnea, chronic obstructive pulmonary disease, and heart failure with preserved ejection fraction: a cardiopulmonary perspective. Am J Respir Crit Care Med. (2020) 201:500. doi: 10.1164/rccm.201909-1780LE

222. Ayas NT, Foster GE, Shah N, Floras J, Laher I. Could adjunctive pharmacology mitigate cardiovascular consequences of obstructive sleep apnea? Am J Respir Crit Care Med. (2019) 200:551-5. doi: 10.1164/rccm.201811-2097PP

223. Lam CSP, Gamble GD, Ling LH, Sim D, Leong KTG, Yeo PSD, et al. Mortality associated with heart failure with preserved vs. Reduced ejection fraction in a prospective international multi-ethnic cohort study. Eur Heart J. (2018) 39:1770-80. doi: 10.1093/eurheartj/ehy005

224. Go YY, Sugimoto T, Bulluck H, Acharyya S, Allen JC, Chia SY, et al. Age and ejection fraction modify the impact of atrial fibrillation on acute heart failure outcomes. Eur J Heart Fail. (2018) 20:821-2. doi: 10.1002/ejhf. 1075
225. Van Aelst LNL, Arrigo M, Placido R, Akiyama E, Girerd N, Zannad F, et al Acutely decompensated heart failure with preserved and reduced ejection fraction present with comparable haemodynamic congestion. Eur J Heart Fail. (2018) 20:738-47. doi: 10.1002/ejhf.1050

226. Brunner-La Rocca HP, Eurlings L, Richards AM, Januzzi JL, Pfisterer ME, Dahlström $U$, et al. Which heart failure patients profit from natriuretic peptide guided therapy? A meta-analysis from individual patient data of randomized trials. Eur J Heart Fail. (2015) 17:1252-61. doi: 10.1002/ejhf.401

227. Bonora M, Wieckowski MR, Sinclair DA, Kroemer G, Pinton P, Galluzzi L. Targeting mitochondria for cardiovascular disorders: therapeutic potential and obstacles. Nat Rev Cardiol. (2019) 16:33-55. doi: 10.1038/s41569-018-0074-0

Conflict of Interest: The authors declare that the research was conducted in the absence of any commercial or financial relationships that could be construed as a potential conflict of interest.

Copyright (c) $2021 \mathrm{Li}$, Zhao and Wang. This is an open-access article distributed under the terms of the Creative Commons Attribution License (CC BY). The use, distribution or reproduction in other forums is permitted, provided the original author(s) and the copyright owner(s) are credited and that the original publication in this journal is cited, in accordance with accepted academic practice. No use distribution or reproduction is permitted which does not comply with these terms. 